\title{
Development of Innovative Measurement Techniques for Fission Product Transport Quantification
}

Daniel Orea, Byung-Hee Choi, Thien Nguyen, Rodolfo Vaghetto, Yassin A. Hassan, and N. K. Anand Texas A\&M University

Piyush Sabharwall

Idaho National Laboratory

May 2020
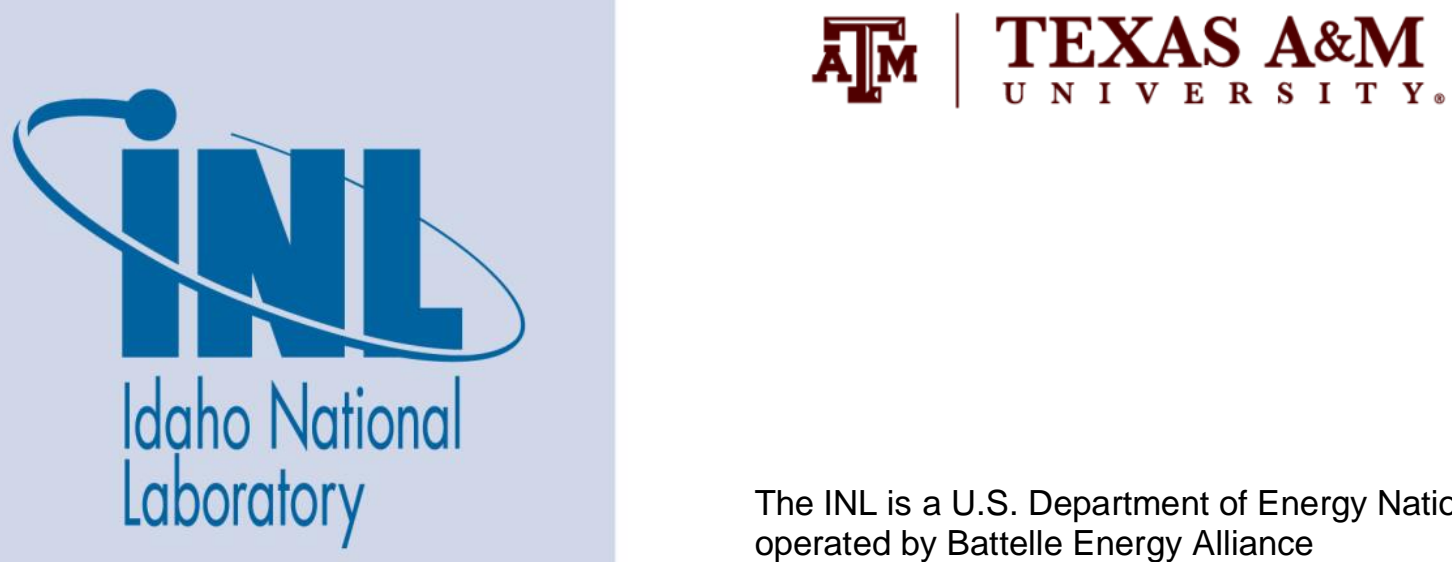

The INL is a U.S. Department of Energy National Laboratory operated by Battelle Energy Alliance 


\section{DISCLAIMER}

This information was prepared as an account of work sponsored by an agency of the U.S. Government. Neither the U.S. Government nor any agency thereof, nor any of their employees, makes any warranty, expressed or implied, or assumes any legal liability or responsibility for the accuracy, completeness, or usefulness, of any information, apparatus, product, or process disclosed, or represents that its use would not infringe privately owned rights. References herein to any specific commercial product, process, or service by trade name, trade mark, manufacturer, or otherwise, does not necessarily constitute or imply its endorsement, recommendation, or favoring by the U.S. Government or any agency thereof. The views and opinions of authors expressed herein do not necessarily state or reflect those of the U.S. Government or any agency thereof. 


\section{Development of Innovative Measurement Techniques for Fission Product Transport Quantification}

Daniel Orea, Byung-Hee Choi, Thien Nguyen, Rodolfo Vaghetto, Y. A. Hassan, and N. K. Anand

Texas A\&M University

Piyush Sabharwall

Idaho National Laboratory

May 2020

\section{Idaho National Laboratory \\ Idaho Falls, Idaho 83415}

http://www.inl.gov

Prepared for the

U.S. Department of Energy

Office of Nuclear Energy

Under DOE Idaho Operations Office

Contract DE-AC07-05ID14517 


\section{EXECUTIVE SUMMARY}

This document provides the progress of a research project at Texas A\&M University (TAMU), led by Idaho National Laboratory (INL), in support of the Versatile Test Reactor (VTR) program and work scope area of gas-cooled fast reactors. The VTR TAMU INL project started in October 2018. The main objective of the project is to characterize transport fission product particulates and gases in the Fission Product Ventilation System (FPVS) of the Gas Fast Reactor (GFR) Cartridge loop to be part of the envisioned Versatile Test Reactor (VTR).

As a first approximation to the FPVS, straight channel geometry widely prevalent in FPVS in GFRs was used for proof of concept studies. The goal was to establish and validate experimental and simulation techniques to characterize particulate transport in straight rectangular channels. In the development of proof of concept facility, the scaling approach was adapted such that the dynamic similarity between the full-scale simplified FPVS and the scaled down experimental facility takes into consideration the following dimensionless numbers, such as the Froude number, Schmidt number, Richardson number, and Grashof number, to characterize physical phenomena and to scale the prototype. It is expected that the scaling approach developed in this study can be applied to investigate the FPVS of the VTR GFR Cartridge Loop.

Second, the report provides an overview of the proof-of-concept test facility, including a particle scaling approach, experimental design and instrumentation, that is built to support the development and implementation of instrumentation and measurement techniques to characterize transport and dynamics of surrogate particles. In this part, a particle scaling approach is developed for the proof-of-concept facility considering graphite dust as a potential surrogate fission product released during accidents and during normal operating conditions. The scaling approach can be achieved by matching the Reynolds number and Stokes number of the fission product and surrogate particles. The proof-of-concept facility is a square cross-section channel with a $1.83-\mathrm{m}$ length. The facility is built from transparent materials to facilitate the measurements of flow and transport of particles in the facility by employing the flow visualization techniques, such as particle image velocimetry (PIV) and particle tracking velocimetry (PTV).

Preliminary results obtained from experimental measurements of the proof-of-concept facility have indicated that the non-intrusive optical measurement techniques, such as PIV and PTV, can be applied to characterize the aerodynamic flow fields and particle deposition. The acquired PIV experimental results showed that particle velocity decreases as they move toward the wall, while the PTV results provided additional information about particle size and particle velocity distribution. 
Numerical studies of particle transport and deposition in the proof-ofconcept facility are performed using various turbulence models such as standard k- $\varepsilon$ (Launder \& Spalding, 1974), Lam-Bremhorst (Lam \& Bremhorst, 1981), Launder-Sharma (Launder \& Sharma, 1974) and LienLeschziner (Lien \& Leschziner, 1993) models. It is found that the LaunderSharma and Lien-Leschziner models performed well in predicting the velocity profiles of the developing flow and fully developed flow. Preliminary results from the simulations suggested that it is necessary to pursue advanced turbulent models, such as Reynolds stress model, to improve the prediction of turbulent kinetic energy and secondary flows in the proof-of-concept channel.

Further work includes performing experiments at various low and high Reynolds numbers to give insight on gravitational and turbulence effects on particle deposition. In addition, measurements on a surface wall to determine the particle size and deposition will be implemented using highresolution cameras and optics paired with the Laser-Induced Fluorescence technique. The surface will be modified with carbon nanotube sheets to determine the effects of the surface on deposition. Numerical simulations will be further explored with advanced turbulence models to capture the secondary flows and with Lagrangian approach for particle tracking to study the effects of gravity, drag, and turbophoresis force. below.

A list of publications produced from the research activities is included

\section{Publications}

1. D. Orea, T. Nguyen, R. Vaghetto, N.K. Anand, Y. Hassan and P. Sabharwall, An Investigation to Develop Measurement Techniques for Quantifying Fission Product Transport in a Gas-cooled Fast Reactor Versatile Test Reactor Program, Transactions of the American Nuclear Society, 120, 1015-1018, 2019.

2. D. Orea, R. Chavez, T. Nguyen, R. Vaghetto, N.K. Anand, Y. Hassan and P. Sabharwall, Experimental Study of Surrogate Particle Transport and Deposition in a Square Channel Using Particle Tracking Technique, International Mechanical Engineering Congress \& Exposition (IMECE 2019), November 8th-14th, Salt Lake City, Utah, 2019.

3. B.H. Choi, D. Orea, T. Nguyen, N.K. Anand, Y. Hassan and P. Sabharwall, Numerical Study of Particle Transport and Deposition in a Horizontal Channel Using a Lagrangian-based Modelling Approach, International Mechanical Engineering Congress \& Exposition (IMECE 2019), November 8th-14th, Salt Lake City, Utah, 2019.

4. B.H. Choi, D. Orea, T. Nguyen, N.K. Anand, Y. Hassan and P. Sabharwall, Numerical Investigation of Fluid Flow in a Square Channel-Versatile Test Reactor Program, Transactions of the American Nuclear Society, 121, 1149-1152, 2019. 
5. D. Orea, R. Chavez, T. Nguyen, R. Vaghetto, N.K Anand, Y. Hassan and P. Sabharwall, Experimental Investigation of Surrogate Particle Transport in a Turbulent Channel Flow-Versatile Test Reactor Program, Transactions of the American Nuclear Society, 121, 11531156, 2019.

6. T. Nguyen, D. Orea, R. Vaghetto, N. K. Anand, Y. A. Hassan and P. Sabharwall, Particle Transport Study in a Horizontal Square Channel Using Particle Imaging and Tracking Velocimetry for Code Validation, Physics of Reactors (PHYSOR 2020), Cambridge, 2020.

7. R. Chavez, D. Orea, B.H. Choi, T. Nguyen, R. Vaghetto, N.K Anand, Y. Hassan and P. Sabharwall, Particle Deposition in a Square ChannelPart I: Experimental Study, Aerosol Science \& Technology, (To be submitted).

8. B.H. Choi, R. Chavez, D. Orea, T. Nguyen, N.K Anand, Y. Hassan and P. Sabharwall, Particle Deposition in a Square Channel- Part II: Numerical Study, Aerosol Science \& Technology, (To be submitted). 


\section{CONTENTS}

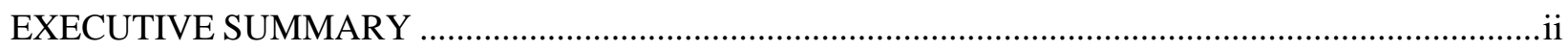

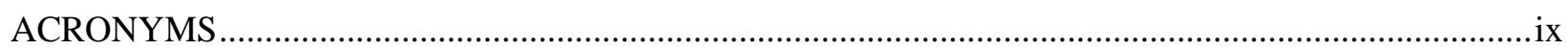

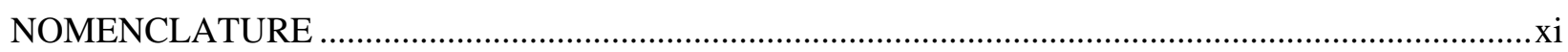

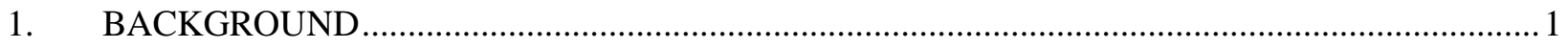

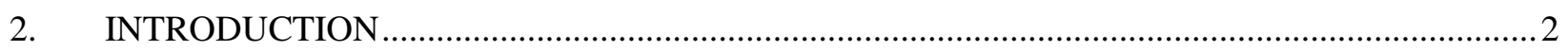

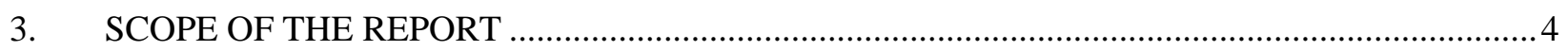

4. SCALING APPROACH OF THE SIMPLIFIED GAS-COOLED REACTOR

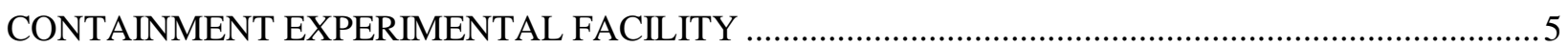

5. PARTICLE SCALING APPROACH OF THE PROOF-OF-CONCEPT TEST FACILITY ............12

6. OVERVIEW OF THE PROOF-OF-CONCEPT TEST FACILITY .............................................. 16

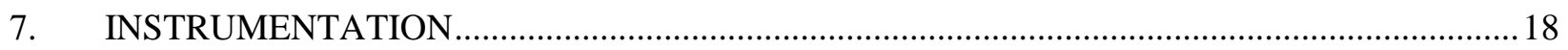

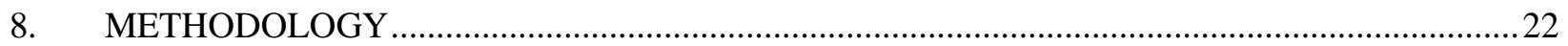

8.1. Aerodynamic Flow Measurements in the Proof-of- Concept Facility Using Aerosol

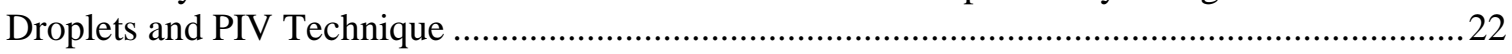

8.2. Particle Transport in the Proof-of-Concept Facility using Surrogate Particles and

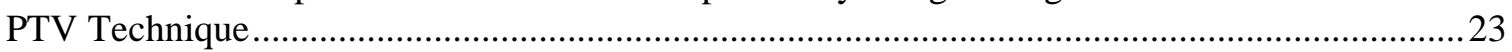

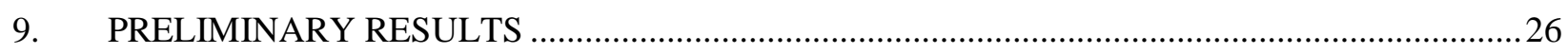

9.1. Results of Aerodynamic Flow Measurements in the Proof-of-Concept Facility Using

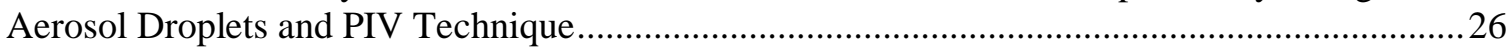

9.2. Results of Particle Transports in the Proof-of- Concept Test Facility Using Surrogate

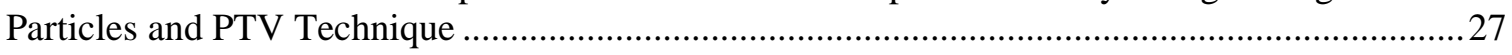

9.3. Uncertainty Analysis on Velocimetry Techniques ...........................................................29

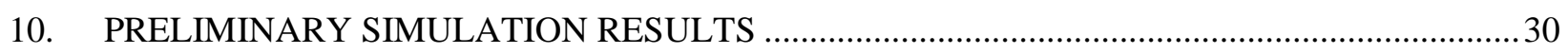

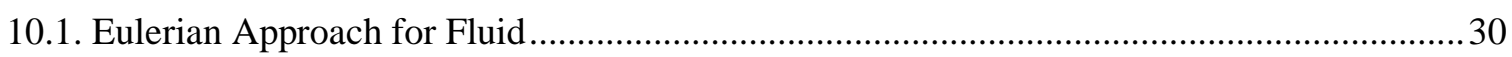

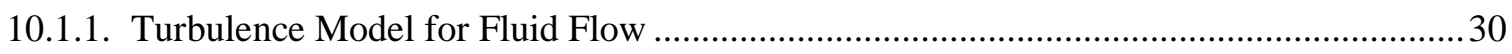

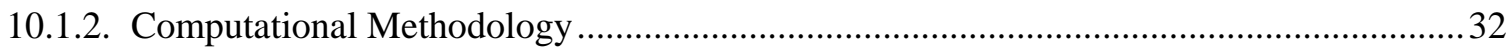

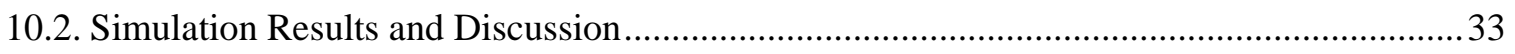

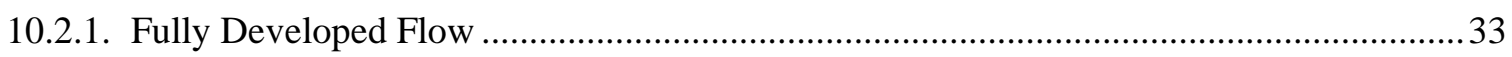

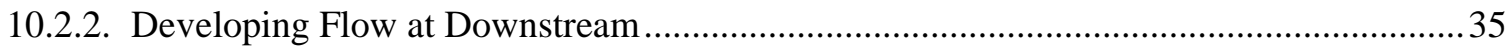

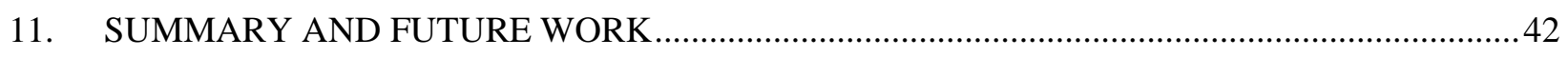

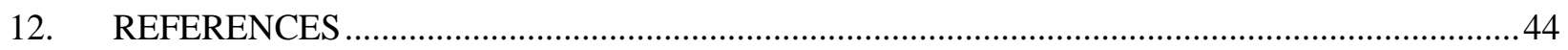




\section{FIGURES}

Figure 6-1. Proof-of-concept test facility and computer-assisted drawing (CAD) of the

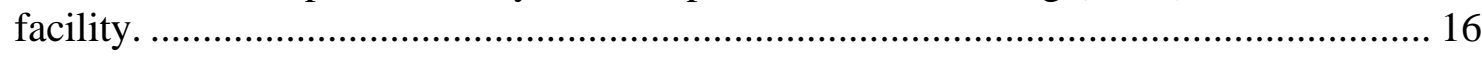

Figure 7-1. Left: continuous 532-nm laser and right: adjustable power supply...................... 18

Figure 7-2. Left: pulse $532 \mathrm{~nm}$ laser and right: adjustable power and frequency. ..................... 18

Figure 7-3. Left: solid-state 532 nm laser and right: power supply...................................... 19

Figure 7-4. Left: a 4 megapixel and right: an 8-megapixel camera........................................ 19

Figure 7-5. High-speed 1.3-megapixel camera.............................................................. 19

Figure 7-6. High-magnification lens for capturing particle deposition in the near-wall

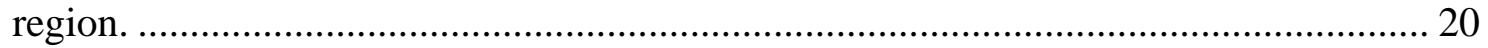

Figure 7-7. Top: Six-jet oil atomizer and bottom: solid-particle reservoir............................. 20

Figure 7-8. Left: air compressor and right: anemometer. ............................................... 21

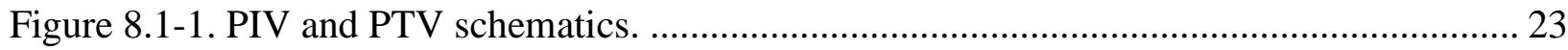

Figure 8.1-2. Left: original, undyed solid particles and right: particles dyed in the

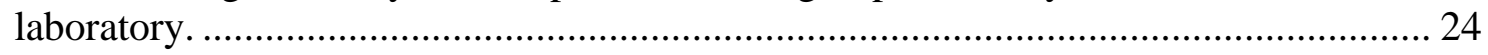

Figure 8.1-3. (Left): high-magnification image of CNT (Right): Full CNT sheet provided

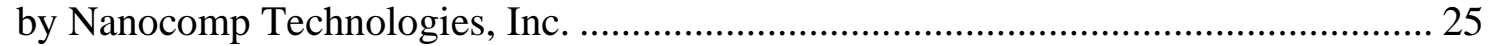

Figure 9-1. $\operatorname{Re}=5,077$. (Left): Mean velocity vector field and velocity magnitude contour. (Right): Profile of mean streamwise velocity in the inlet section.

Figure 9-2. $\operatorname{Re}=5,077$. Near-wall measurements. Left: mean velocity vector magnitude contour. Right: turbulent kinetic energy contour.

Figure 9-3. Left: instantaneous-velocity vector field overlaid on an experimental image. Right: histogram of particle sizes. 28

Figure 9-4. Histograms of (left) particle U velocity component and (right) particle V

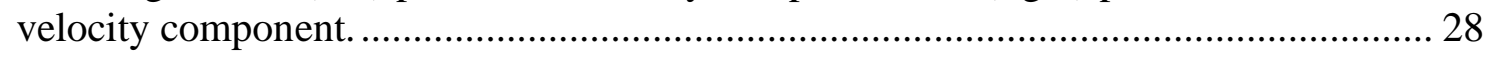

Figure 9-5. Normalized particle concentration along a vertical line profile............................. 29

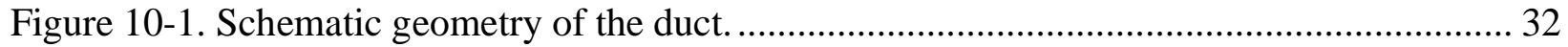

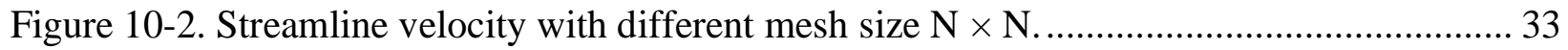

Figure 10-3. Comparison of streamwise velocity with different models. Log (Left) and linear (right) plot for location y.

Figure 10-4. Comparisons between PIV and CFD in the downstream region of the channel with standard $\mathrm{k}-\epsilon$ model (up) $\mathrm{Re}_{\mathrm{c}}=3,600$, (middle) $\mathrm{Re}_{\mathrm{c}}=5,100$ and (bottom) $\operatorname{Re}_{c}=6,100$.

Figure 10-5. Comparisons between PIV and CFD in the downstream region of the channel with Lam-Bremhorst model (up) $\operatorname{Re}_{c}=3,600$, (middle) $\operatorname{Re}_{c}=5,100$ and (bottom) $\operatorname{Re}_{c}=6,100$. 
Figure 10-6. Comparisons between PIV and CFD in the downstream region of the channel with Laundar-Sharma model (up) $\operatorname{Re}_{c}=3,600$, (middle) $\operatorname{Re}_{c}=5,100$ and (bottom) $\operatorname{Re}_{\mathrm{c}}=6,100$.

Figure 10-7. Comparisons between PIV and CFD in the downstream region of the channel with Lien-Leschziner model (up) $\operatorname{Re}_{c}=3600$, (middle) $\operatorname{Re}_{c}=5100$ and (bottom) $\operatorname{Re}_{\mathrm{c}}=6100$.

Figure 10-8. Evolution of velocity profiles, $U$ velocity (left) and kinetic-energy profiles for turbulence (right) with different locations along $\mathrm{x}, \mathrm{z}=\mathrm{h} / 2$ with $\operatorname{Re}_{\mathrm{c}}=5,100$, LS model is employed.

Figure 10-9. Secondary velocity contour at downstream of $\operatorname{Re}_{c}=5,100$. The LaunderSharma model is employed. 


\section{TABLES}

Table 4-1. Dimensionless parameters in the scaling of facility. ........................................... 11

Table 5-1: Scaled Model Particle Diameter and Fluid Velocity .............................................. 14

Table 5-2. GA Fission Product and Hight Temperature Absorber (HTA) Properties................. 15

Table 9-1. Constant parameters used to calculate Reynolds number. ..................................... 26

Table 9-2. Fluid flow rates and Reynolds number................................................................ 26

Table 10-1. Closure coefficient for k- $\varepsilon$ model. ................................................................ 31

Table 10-2 Terms and boundary condition for each model................................................ 31

Table 10-3 Damping coefficient for each model. ............................................................. 31

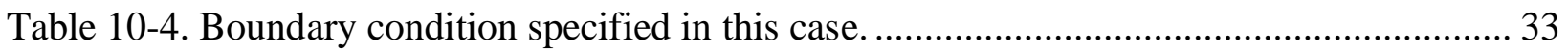

Table 10-5. Ratio of centerline velocity to bulk velocity at fully developed condition. ............. 35 


\section{ACRONYMS}

\begin{tabular}{|c|c|}
\hline ARSM & Algebraic Stress Model \\
\hline CAD & Computer-Assisted Drawing \\
\hline CCD & Charged Couple Device \\
\hline CFD & Computational Fluid Dynamics \\
\hline CL & Cartridge Loops \\
\hline $\mathrm{CNT}$ & Carbon Nanotube \\
\hline DEHS & Di-Ethyl-Hexyl-Sebacate \\
\hline DNS & Direct Numerical Simulation \\
\hline DOE & Department of Energy \\
\hline DPIV & Digital Particle Image Velocimetry \\
\hline ELSY & European Lead System \\
\hline FPVS & Fission Product Venting System \\
\hline GFR & Gas-Cooled Fast Reactor \\
\hline HTGR & High-Temperature Gas-Cooled Reactor \\
\hline INL & Idaho National Laboratory \\
\hline $\mathrm{LB}$ & Lam-Bremhorst model \\
\hline LIF & Laser-Induced Fluorescence \\
\hline LL & Lien-Leschziner model \\
\hline $\mathrm{LS}$ & Launder-Sharma model \\
\hline MSFR & Molten Salt Fast Reactor \\
\hline PGSFR & Prototype Generation-IV Sodium-Cooled Fast Reactor \\
\hline PIRT & Phenomena Identification and Ranking Table \\
\hline PIV & Particle-Image Velocimetry \\
\hline PTV & Particle-Tracking Velocimetry \\
\hline RANS & Reynolds-Averaged Navier-Stokes \\
\hline $\mathrm{RPC}$ & Robust Phase Correlation \\
\hline RSM & Reynolds Stress Model \\
\hline STD & Standard k- $\varepsilon$ turbulence model \\
\hline TAMU & Texas A\&M University \\
\hline TKE & Turbulence Kinetic Energy \\
\hline VLPC & Vented Low-Pressure Confinement \\
\hline
\end{tabular}




\section{NOMENCLATURE}

\begin{tabular}{|c|c|}
\hline$\alpha$ & Image magnification factor \\
\hline$\beta$ & Thermal expansion coefficient \\
\hline$\epsilon$ & Dissipation of turbulence kinetic energy \\
\hline$\tilde{\epsilon}$ & Modified dissipation, $\tilde{\epsilon}=\epsilon-D$ \\
\hline$\mu$ & Dynamic viscosity \\
\hline$\mu_{f, m}$ & Fluid Viscosity of Experimental Facility Model \\
\hline$\mu_{f, P}$ & Fluid Viscosity of Reactor Building Prototype \\
\hline$v$ & Kinematic viscosity \\
\hline$v_{T}$ & Kinematic eddy viscosity \\
\hline$\rho_{f, m}$ & Fluid Density Experimental Facility Model \\
\hline$\rho_{f, P}$ & Fluid Density Reactor Building Prototype \\
\hline$\sigma_{k}, \sigma_{\epsilon}$ & Closure model coefficients for $k-\epsilon$ model \\
\hline$\tau_{\text {wall }}^{*}$ & Wall shear stress \\
\hline$\Psi$ & Dimensionless number \\
\hline$C_{d p}$ & Coefficient of Particle Diameter \\
\hline$C_{U}$ & Coefficient of Fluid Velocity \\
\hline $\mathrm{C}_{\mu}, \mathrm{C}_{\epsilon 1}, \mathrm{C}_{\epsilon 2}$ & Closure model coefficients for $k-\epsilon$ model \\
\hline$d_{\text {part }, m}$ & Particle Diameter of Experimental Facility Model \\
\hline$d_{\text {part }, p}$ & Particle Diameter of Reactor Building Prototype \\
\hline $\mathrm{D}$ & Molecular Diffusivity \\
\hline$D_{H}$ & Hydraulic diameter of the channel \\
\hline $\mathrm{D}, \mathrm{E}$ & Extra source terms used in turbulence model \\
\hline$f_{\mu}$ & Damping function for viscosity \\
\hline$f_{1}$ & Damping function for production of dissipation \\
\hline$f_{2}$ & Damping function for dissipation of dissipation \\
\hline$f_{\text {scale }}$ & Geometric Scaling Factor \\
\hline $\mathrm{Fr}$ & Froude number \\
\hline $\mathrm{g}$ & Gravitational acceleration \\
\hline$G r$ & Grashof number \\
\hline$h$ & Half-height of the channel \\
\hline$k$ & Turbulence kinetic energy (TKE) \\
\hline$l_{n}$ & Distance from nearest wall \\
\hline$L$ & Characteristic length \\
\hline$P$ & Pressure \\
\hline$\widehat{P}$ & Averaged pressure \\
\hline$P_{k}$ & Production of kinetic energy \\
\hline
\end{tabular}




\begin{tabular}{|c|c|}
\hline $\operatorname{Re}$ & Reynolds number \\
\hline$R i$ & Richardson number \\
\hline $\operatorname{Rea}$ & Reynolds number of aerosol droplets \\
\hline $\operatorname{Re}_{p}$ & Reynolds number of polypropylene particles \\
\hline$R e_{t}$ & Turbulence Reynolds number, $k^{2} / \epsilon v$ \\
\hline$R e_{c}$ & Centerline Reynolds number, $U_{c}(2 h) / v$ \\
\hline$R e_{b}$ & Bulk Reynolds number, $U_{b}(2 h) / v$ \\
\hline$R e_{\tau}$ & Friction Reynold number, $h u_{\tau}^{*} / v$ \\
\hline$S t k$ & Stokes number \\
\hline$S c$ & Schmidt number \\
\hline$T$ & Temperature \\
\hline$U$ & Characteristic velocity \\
\hline$U_{c}$ & Velocity at centerline \\
\hline$U_{b}$ & Bulk velocity \\
\hline$U_{f, m}$ & Fluid Velocity of Experimental Facility Model \\
\hline$U_{f, p}$ & Fluid Velocity of Reactor Building Prototype \\
\hline$U_{i}$ & Averaged velocity along the $i$-direction \\
\hline$U_{\text {mean }}, V_{\text {mean }}$ & Time-averaged streamwise, wall-normal velocities \\
\hline$u, v$ & Instantaneous streamwise, wall-normal velocities \\
\hline$u^{\prime}, v^{\prime}$ & Fluctuating streamwise, wall-normal velocities \\
\hline$u_{\tau}^{*}$ & Friction velocity, $\left(\frac{\tau_{\text {wall }}^{*}}{\rho}\right)^{0.5}$ \\
\hline$\overline{u_{\imath}^{\prime} u_{\jmath}^{\prime}}$ & Averaged Reynolds stress \\
\hline$x, y$ & Streamwise, wall-normal directions \\
\hline$\Delta X$ & Particle displacement in pixel \\
\hline$\Delta t$ & Inter-frame time interval \\
\hline
\end{tabular}




\section{Development of Innovative Measurement Techniques for Fission Product Transport Quantification}

\section{BACKGROUND}

The Versatile Test Reactor (VTR) program under the U.S. Department of Energy (DOE) aims to design an irradiation facility to provide a broad range of testing capabilities for nuclear fuels and materials. The VTR facility is preliminarily proposed as a sodium-cooled 300 MW fastspectrum test reactor to aid in efforts of research and develop advance fuels, components, and instrumentation. The proposed reactor will have five potential locations for instrumented assemblies and/or cartridge loops (CL). These CL will have the ability to be cooled using Sodium, Lead, Molten Salt, or Helium.

A Gas-Cooled Fast Reactor (GFR) combines the advantages of fast-spectrum systems (longterm sustainability of uranium resources and waste minimization) with improved performances (high thermal-cycle efficiency and industrial use of the generated heat) due to the high temperature achieved. During operation of the CL, fission products may be released into the loop by various mechanisms. These mechanisms include depressurization events, phenomena connected to the transport, deposition, and possible resuspension of particulates. Fission products released in the CL due to these mechanisms add to the radiation source within the loop.

Development and implementation of new specialized techniques to quantify the transport and deposition of fission products in the loop are essential for successful development of the CLi.

The purpose of this study is to provide the first-year progress of a research project at Texas A\&M University (TAMU), led by Idaho National Laboratory (INL), supporting the VTR program and work scope area of GFR CL development. The VTR TAMU INL project started in October 2018. This document includes the main objectives of the project; a scaling analysis applied to the experimental facilities; the experimental methodology, including instrumentation and techniques applied; and up-to-date results from the experimental and numerical studies.

i Note that this work can also be applied to a GFR confinement building. 


\section{INTRODUCTION}

TAMU is participating in the U.S. Department of Energy (DOE) Office of Nuclear Energy's VTR program to develop instrumentation and tools for a proposed fast-spectrum test reactor.

The goal of the research project is to develop and implement techniques to quantify the transport and deposition of fission products in the primary system of the VTR GFR cartridge loop and in Fission Product Venting System (FPVS) of the GFR cartridge loop. The proposed work is to develop advanced high spatial and temporal resolution techniques to measure the concentration of surrogate fission products in prototypical environments. These techniques will be useful to support the quantification of fission-product release, transport, deposition, and resuspension. These techniques should be flexible and easily applicable to fully satisfy the future test needs.

In order to carry out this study, experiments were conducted in proof-of-concept channel to characterize deposition of surrogate particles and numerical simulations were conducted to predict flow filed and deposition of surrogate particles in the proof-of-concept channel.

The scopes of the proposed project have following tasks:

- Phenomena Identification and Ranking Table (PIRT). The FPVS in the GFR Cartridge Loop is a critical defense-in-depth feature for the prevention of contamination of the Helium loop. In addition, the FPVS prevents over-pressurization of the fuel elements by relieving fission product gas pressure. In FPVS the radio nuclide particles that have been aerosolized through both 'passive' (natural) processes and 'active' (mechanical) processes are present. In the FPVS of VTR GFR Cartridge Loop designs, this is primarily driven by natural phenomena such as impaction, gravitational settling, thermophoresis, diffusiophoresis, and turbophoresis. As necessary particulate transportation, suspension, and settling in VTR Cartridge Loop space will be addressed. A PIRT will be developed for the VTR GFR experimental facility to identify and rank the important phenomena involved in the generation, transport, deposition, and resuspension of fission products in the VTR GFR Cartridge Loop. Published research by the collaborators and other national and international institutions will be collected and reviewed.

- Scaling. The test facility proposed was designed following certain scaling relationships that may be revised and adapted to the proposed work. It is expected that the scaling approach developed in this study can be applied to investigate the FPVS of the VTR GFR Cartridge Loop. The GFR Cartridge Loop operates at high temperatures $(\sim 850$ o C) and high pressures ( 13 MPa) hence prior to building an opaque high strength prototypical scaled FPVS, it is necessary to establish measurement and simulation techniques in scaled proof-of-concept channel. Correlations obtained in terms of dimensionless parameters using the experimental and simulation data for particle and fission gas transport in the scaled proof-of-concept channel can be used to design and characterize fission product transport in a prototypical scaled VTR GFR Cartridge Loop.

- Development and Application of Measurement Techniques. The goal is to develop and apply techniques to measure solid fission product concentrations. This will be achieved by combining a source of illumination (laser) and high speed and resolution cameras (details discussed in chapter 8). As the particles move through the illumination volume (sheet), the scattered light is detected and recorded by the cameras. The images recorded will be post-processed by a special particle tracking and sizing algorithms. 
The above-mentioned tasks are planned in the proposal submitted by TAMU. However, it is noted that the project scope and tasks could be modified during the project to accommodate the development of the GFR Cartridge Loop within the VTR program. In addition, the participation of industry partners in the VTR program is anticipated to aid in the revision and improvement of the project scope and tasks to further refine and advance the proposed methodologies. 


\section{SCOPE OF THE REPORT}

This document describes the research progress of the project at TAMU under VTR program and GFR scope. The VTR TAMU INL project started in October 2018.

First, the report provides an overview of the proof-of-concept facility (channel), including the scaling approach and the experimental design.

Second, the report describes the experimental methodology currently in development stage and its application to study surrogate particle transport through air in a horizontal, square channel, which is used as a proof-of-concept test facility. Details of the experimental methodology include the scaling approach for surrogate particles, instrumentation, measurements techniques, and the application of the developed measurement techniques to study surrogate particle transport in the proof-of-concept test facility. Preliminary results obtained from the experimental measurements and numerical simulations of the studied configurations are included in the report. 


\section{SCALING APPROACH OF THE SIMPLIFIED GAS-COOLED REACTOR CONTAINMENT EXPERIMENTAL FACILITY}

This chapter describes the scaling methodology applied to the experimental facility of a simplified FPVS of the VTR GFR Cartridge Loop. As stated earlier the scaling is necessary to establish measurement techniques using a transparent scaled proof of concept channel that operates at standard temperature and pressure (STP) conditions as the prototypical GFR Cartridge Loop will operate at high temperatures and pressures built with opaque metals. The scaling methodology adopted is based on the non-dimensional similarity approach to evaluate the main dimensions and other features of the experimental facility in order to mimic the main characteristics of a simplified reactor primary system and building design. This approach will preserve the physical phenomena in the prototype and the experimental facility. Dominant thermal-hydraulics phenomena and the corresponding non-dimensional parameters derived from the full-scale prototype and the downscaled-facility features are based on previous related research (Haynes, et al., 2017; Yang, et al., 2018).

Dimensionless parameters, such as Froude, Schmidt, Richardson, Grashof, and Reynolds numbers, which govern the thermal-fluid dynamics of the studied phenomena were considered. It is noted that the non-dimensional parameters used in the scaling approach can be further applied to the VTR GFR Cartridge Loop design. For example, fission gases and fission particles could be produced during irradiation tests and be present in the FPVS of VTR GFR Cartridge Loop. Phenomena, such as gas diffusion and mixing, transport, particle deposition and resuspension, could occur.

To select scaling parameters for experiments with thermal-fluid transport, researchers first identify characteristic length $(L)$, velocity $(U)$, temperature $(T)$, and time $(t)$ scales to derive the dimensionless parameters. For clarity of the scaling relationships, the following terms are used:

- Model (" $m$ "). This term identifies the scaled experimental facility to simulate the phenomena expected in a full-scale gas-cooled reactor building.

- Prototype (" $p$ "). This term identifies the design for a simplified, full-scale GFR Cartridge Loop.

During the transportation of the GFR Cartridge in and out the test location, there is a potential for helium leaks due to high pressures. Another potential accident scenario is a failure of the FPVS which results in the mixing of fission product gases (e.g., xenon and krypton) and helium. The Froude number should be considered because the gas is a mixture composed of two fluids. Froude number represents the ratio of inertial forces to gravitational forces defined as,

$$
F r=\frac{U^{2}}{g \rho^{\prime} L}
$$

where $\mathrm{g}$ is the acceleration due to gravity, $\rho^{\prime}=\frac{\Delta \rho}{\rho}=\frac{\rho_{H e}-\rho_{\text {air }}}{\rho_{\text {air }}}$, and $\rho$ is the density of the fluid.

The diffusion process between two fluids is characterized by the Schmidt number, which is the ratio of the momentum diffusivity to the mass diffusivity. 


$$
S c=\frac{v}{D}
$$

where $v$ is kinematic viscosity (momentum diffusivity) and D is the molecular diffusivity. In addition, the flow is affected by buoyant forces. The Richardson number,

$$
R i=\frac{g \beta \Delta T L}{U^{2}}
$$

where $\beta$ is the thermal expansion coefficient, and $\Delta \mathrm{T}$ is the temperature difference between fluids, should be also considered. The Grashof number also considers buoyancy, which is the ratio of the buoyant to viscous forces acting on a fluid, helping characterize natural convection.

$$
G r=\frac{g L^{3} \beta \Delta T}{v^{2}}
$$

Finally, it is reasonable to expect that the experiments on the scaled facility are necessarily done by imposing boundary and initial conditions obtained from the prototype simulations (or field measurements). Under these circumstances, the Reynolds number, $R e$, should be also considered.

$$
R e=\frac{U L}{v}
$$

The similarity of the Froude, Richardson, and Reynolds numbers are concerned with length, temperature, and velocity scaling, respectively. The Schmidt number similarity is related to the thermal-fluid properties of Helium and air. In order to guarantee the thermal-fluid dynamics similarity of the model to the prototype, the ratio of the dimensionless numbers is set to unity:

$$
\Psi_{R}=\frac{\Psi(\text { model })}{\Psi(\text { prototype })}=\frac{\Psi_{m}}{\Psi_{p}}=1
$$

where subscripts $\mathrm{m}, \mathrm{p}$ and R denote the "model," the "prototype" and their ratio, respectively.

Similarities for the non-dimensional parameters are given below.

Froude number:

$$
F r_{R}=\frac{F r_{m}}{F r_{p}}=\left(\frac{U^{2}}{g\left(\frac{\Delta \rho}{\rho}\right) L}\right)_{m}\left(\frac{U^{2}}{g\left(\frac{\Delta \rho}{\rho}\right) L}\right)_{p}^{-1}
$$

Schmidt number:

$$
S c_{R}=\frac{S c_{m}}{S c_{p}}=\left(\frac{v}{D_{d}}\right)_{m}\left(\frac{v}{D_{d}}\right)_{p}^{-1}
$$

Richardson number: 


$$
R i_{R}=\frac{R i_{m}}{R i_{p}}=\left(\frac{g \beta \Delta T L}{U^{2}}\right)_{m}\left(\frac{g \beta \Delta T L}{U^{2}}\right)_{p}^{-1}
$$

Grashof number:

$$
G r_{R}=\frac{G r_{m}}{G r_{p}}=\frac{(\beta \Delta T)_{m}}{(\beta \Delta T)_{p}} \frac{\left(\frac{g L^{3}}{v^{2}}\right)_{m}}{\left(\frac{g L^{3}}{v^{2}}\right)_{p}}
$$

Reynolds number:

$$
R e_{R}=\frac{R e_{m}}{R e_{p}}=\left(\frac{U L}{v}\right)_{m}\left(\frac{U L}{v}\right)_{p}^{-1}
$$

Similarity between the model and the prototype for the Grashof number can be split into two ratios that can be treated separately as shown in Eq. 10. The first ratio in the Grashof similarity yields to,

$$
\frac{(\beta \Delta T)_{m}}{(\beta \Delta T)_{p}}=1 \rightarrow(\beta \Delta T)_{m}=(\beta \Delta T)_{p} \rightarrow \frac{\beta_{m}}{\beta_{p}}=\frac{\Delta T_{p}}{\Delta T_{m}}
$$

Applying the ideal gas $\beta=\frac{1}{T}$ gives,

$$
\frac{\Delta T_{m}}{\Delta T_{p}}=\frac{T_{m}}{T_{p}}
$$

The second ratio in the Grashof similarity yields,

$$
\frac{\left(\frac{g L^{3}}{v^{2}}\right)_{m}}{\left(\frac{g L^{3}}{v^{2}}\right)_{p}}=1 \rightarrow\left(\frac{g L^{3}}{v^{2}}\right)_{m}=\left(\frac{g L^{3}}{v^{2}}\right)_{p} \rightarrow\left(\frac{L_{m}}{L_{p}}\right)^{\frac{3}{2}}=\frac{v_{m}}{v_{p}}=\frac{\mu_{m} \rho_{p}}{\mu_{p} \rho_{m}}
$$

Ideal gas density:

$$
\rho(T, P)=\rho_{0}\left(T_{0}, P_{0}\right) \cdot \frac{P}{P_{0}} \cdot \frac{T_{0}}{T}
$$

Dynamic viscosity:

$$
\mu(T)=\mu_{0}\left(T_{0}\right) \cdot\left(\frac{T}{T_{0}}\right)^{\frac{1}{2}}
$$

$T_{0}, P_{0}$ and $\rho_{0}$ are reference absolute temperatures, pressures and densities respectively. Choosing $P_{0 p}=P_{0 m}$ and $T_{0 p}=T_{0 m}$, and substituting Eq. 15 and Eq. 16 into Eq. 14, the pressure relationship between the model and prototype can be expressed as, 


$$
\frac{P_{m}}{P_{p}}=\frac{v_{0 m}}{v_{0 p}} \cdot\left(\frac{T_{m}}{T_{p}}\right)^{\frac{3}{2}} \cdot\left(\frac{L_{p}}{L_{m}}\right)^{\frac{3}{2}}
$$

Since the model will use the same fluids as in the prototype (i.e. helium and air), the ratio of reference for kinematic viscosity is $\frac{v_{0 m}}{v_{0 p}}=1$. Assuming working pressures of the model and prototype during the refilling phase are approximately equal $\left(P_{m} \cong P_{p}\right)$, Eq. 17 can be combined with Eq. 13 to give,

$$
\frac{L_{m}}{L_{p}}=\frac{T_{m}}{T_{p}}=\frac{\Delta T_{m}}{\Delta T_{p}}=\frac{1}{f_{\text {scale }}}
$$

where $f_{\text {scale }}$ is the geometrical scaling factor between the prototype and the model. Reynolds number similarity leads to,

$$
\frac{U_{m} L_{m}}{U_{p} L_{p}}=\frac{v_{m}}{v_{p}}=\frac{\mu_{m} \rho_{p}}{\mu_{p} \rho_{m}}
$$

Applying the ideal gas density and viscosity gives,

$$
\frac{U_{m}}{U_{p}}=\left(\frac{L_{m}}{L_{p}}\right)^{\frac{1}{2}}=\left(\frac{1}{f_{\text {scale }}}\right)^{\frac{1}{2}}
$$

Equation 20 shows that the Reynolds number can be matched for the model and prototype by adjusting the velocity. Froude similarity shows that the ratio of the velocity scale is the square root of the length scale ratio and the density difference ratio, shown in Eq. 21.

$$
F r_{R}=\frac{F r_{m}}{F r_{p}}=\left(\frac{U_{m}}{U_{p}}\right)^{2} \cdot\left(\frac{\left(\frac{\Delta \rho}{\rho}\right)_{p}}{\left(\frac{\Delta \rho}{\rho}\right)_{m}}\right) \cdot\left(\frac{L_{p}}{L_{m}}\right)=\left(\frac{\left(\frac{\Delta \rho}{\rho}\right)_{p}}{\left(\frac{\Delta \rho}{\rho}\right)_{m}}\right)
$$

Froude similarity is guaranteed if the density difference can be maintained between the model and prototype. Note that with the determined geometrical scaling factor and experimental conditions, distortions in the scaled experiments can be estimated. For example, considering the matching of Froude and Richardson numbers between the model and prototype, similarity conditions will give,

$$
\left(\frac{\beta_{m}}{\beta_{p}}\right)\left(\frac{\Delta T_{m}}{\Delta T_{p}}\right) \frac{\left(\frac{\Delta \rho}{\rho}\right)_{p}}{\left(\frac{\Delta \rho}{\rho}\right)_{m}}=F r_{R} R i_{R}
$$

The same can be derived for other paired similarities. 
Schmidt and Reynolds numbers:

$$
\frac{U_{m}}{U_{p}} \cdot \frac{L_{m}}{L_{p}}=R e_{R} \frac{v_{m}}{v_{p}}=R e_{R} S c_{R}\left(\frac{D_{d m}}{D_{d p}}\right)
$$

Richardson and Reynolds numbers:

$$
\left(\frac{L_{m}}{L_{p}}\right)^{3}=R e_{R}^{2} R i_{R}\left(\frac{v_{m}^{2}}{v_{p}^{2}}\right)\left(\frac{\beta_{p}}{\beta_{m}}\right)\left(\frac{\Delta T_{p}}{\Delta T_{m}}\right)=R e_{R}^{2} R i_{R} S c_{R}^{2}\left(\frac{D_{d m}}{D_{d p}}\right)^{2}\left(\frac{\frac{\Delta T_{p}}{T_{p}}}{\frac{\Delta T_{m}}{T_{m}}}\right)\left(\frac{v_{m}^{2}}{v_{p}^{2}}\right)
$$

Schmidt, Reynolds and Froude numbers:

$$
\left(\frac{U_{m}}{U_{p}}\right)^{3}=R e_{R} S c_{R} F r_{R}\left(\frac{D_{d m}}{D_{d p}}\right) \frac{\left(\frac{\Delta \rho}{\rho}\right)_{m}}{\left(\frac{\Delta \rho}{\rho}\right)_{p}}=\frac{R e_{R} S c_{R}}{R i_{R}}\left(\frac{D_{d m}}{D_{d p}}\right)\left(\frac{\frac{\Delta T_{m}}{T_{m}}}{\frac{\Delta T_{p}}{T_{p}}}\right)
$$

The geometrical scaling factor shown in Eq. 18 needs to be determined to account for various factors which include:

- Construction materials and techniques to be adopted for the test facility.

- Optimal spatial resolution of measurements to be performed during the experiments.

- Desired overall dimensions of the test facility and the size of the venting flow paths and leak paths.

Following are considerations to the above factors contributing to the determination of the geometrical scaling factor.

Construction materials and techniques:

To allow the use of visualization techniques during the experimental activity, the proposed experimental facility should be constructed using clear plastic material (polycarbonate). The visualization techniques already developed at Texas A\&M University and currently in use for similar experimental apparatus will be adopted to construct the proposed facility. For the use of such construction materials and techniques, the optimal size of the experimental facility must be limited to account for factors such as total weight and deformation. Larger sizes may increase the weight of the panels constituting the cavities of the experimental facility and causing possible deformation of the sides of the cavities.

Spatial resolution of measurements:

The determination of the geometrical scaling factor should account for the desired spatial resolution of the measurements (temperature, pressure, and gas concentration) to be performed during the experimental activity. In general, larger cavities may reduce the spatial resolution of the 
measurements and require the installation of a larger number of instruments (thermocouples, pressure transducers, concentration probes).

Size of venting flow paths and leak paths:

It can be expected that some venting paths and leak paths will have small sizes with respect to the overall dimensions of the GFR Cartridge Loop. Therefore, the geometrical scaling factor should be determined to avoid very small flow paths associated with the venting and leak paths in the experimental facility. Very small flow paths are normally difficult to construct, and they may also limit the ability to perform measurements in specific locations. Flow paths whose sizes can range from $10 \mathrm{~mm}$ to $30 \mathrm{~mm}$ are suitable to easily allow the installation of instrumentation (probes) or the performance of flow visualization (camera, laser).

In summary, these above considerations have suggested that the geometrical scaling factor should be determined so that the experimental facility should not be too large to address challenges associated with construction, and spatial resolution of measurements. On the other hand, the experimental facility with a given geometrical scaling factor should not be too small that it could yield very small sizes of venting flow paths, and that could limit the ability to make measurements. Finally, one should also consider the availability of material in required sizes and the cost.

Table 4-1 provides a summary for the non-dimensional numbers considered based on physical phenomenon. The Froude number represent the effects of gravity current or horizontal stratification to the gas mixture within the containment volume. With the presence of gas mixture, the Froude number will take into account the initial momentum of gas indicated by $U^{2}$ and the gravitational forces indicated by $g \frac{\Delta \rho}{\rho} L$, which related the ratio of density difference between the gases. If the phenomenon of interest is the mixing of two fluids (gases or liquids) flowing horizontally with different densities, the Froude number will be important to consider in the scaling analysis. However, one may not need to use the same kinds of fluids in the prototype (CL) to the model (experiments) to obtain the similarity of the Froude number. Such Froude similarity could be achieved using different kinds of fluids in the experimental facility provided that the initial momentum of fluids, the ratio of density difference and the experimental length scale are appropriately chosen. 
Table 4-1. Dimensionless parameters in the scaling of facility

\begin{tabular}{|c|c|c|}
\hline $\begin{array}{c}\text { Dimensionless } \\
\text { Number }\end{array}$ & Analytical Form & Phenomenon \\
\hline $\begin{array}{c}\text { Geometrical Scaling } \\
\text { Factor }\end{array}$ & $f_{\text {scale }}=\frac{L_{p}}{L_{m}}$ & - \\
\hline Froude Number & $F r=U^{2} /\left(g \frac{\Delta \rho}{\rho} L\right)$ & Gravity Current \\
\hline Schmidt Number & $S c=\frac{v}{D_{A B}}$ & Molecular Diffusion \\
\hline Richardson Number & $R i=\frac{g \beta \Delta T L}{U^{2}}$ & Vertical Stratification \\
\hline Grashof Number & $G r=g \beta \Delta T L^{3} / v^{2}$ & Natural Circulation \\
\hline Reynolds Number & $R e=\frac{U L}{v}$ & Fluid Flow Behavior \\
\hline
\end{tabular}




\section{PARTICLE SCALING APPROACH OF THE PROOF-OF-CONCEPT TEST FACILITY}

In the case of a VTR GFR Cartridge Loop, fission products may be carried away within the loop by the coolant. One potential source term during an accident scenario is graphite dust; it has shown affinity to fission products (Moormann, 2008; Kissane, 2009; Zhang, et al., 2017). Therefore, it is important to analyze particles within the prototype Cartridge Loop and scale the particle size and density to be used in the model.

To determine the physical properties of potential fluid flow along with particle size and density that can be used in the proof-of-concept test facility, the following dimensionless numbers are crucial. The Reynolds number will be considered to account for the similarity between flow conditions of the prototype and model. The Reynolds number for this scaling approach is defined as,

$$
R e_{f}=\frac{U_{f} \rho_{f} L}{\mu_{f}}
$$

where $U_{f}$ is the fluid velocity, $\rho_{f}$ is the fluid density, and $\mu_{f}$ is the fluid dynamic viscosity.

The Stokes number will be considered to characterize the particles in the flow and defined as,

$$
S t k=\frac{\rho_{\text {part }} d_{\text {part }}^{2}}{18 \mu_{f}} \frac{U_{f}}{L}
$$

where "part" indicates particles, $\rho_{\text {part }}$ represents the particle density, and $d_{\text {part }}$ is the particle diameter. Stokes number is a ratio of the characteristic time of a particle to the characteristic time of the flow.

It is important to note that at the initial stage, experiments will be performed under isothermal conditions. It is assumed that the system is filled with a gas. The ratio of the non-dimensional numbers is imposed equal to unity to guarantee fluid dynamic similarity (Eq. 6). Similarities for Reynolds and Stokes are shown below.

Reynolds number similarity:

$$
R e_{\mathrm{R}}=\frac{R e_{m}}{R e_{p}}=\left(\frac{U_{f} \rho_{f} L}{\mu_{f}}\right)_{m} /\left(\frac{U_{f} \rho_{f} L}{\mu_{f}}\right)_{p}
$$

Stokes number similarity:

$$
S t k_{\mathrm{R}}=\frac{S t k_{m}}{S t k_{p}}=\left(\frac{\rho_{\text {part }} d_{\text {part }}^{2}}{18 \mu_{f}} \frac{U_{f}}{L}\right)_{m} /\left(\frac{\rho_{\text {part }} d_{\text {part }}^{2}}{18 \mu_{f}} \frac{U_{f}}{L}\right)_{p}
$$

From Reynolds number similarity, the fluid velocity scale can be algebraically solved in terms of fluid properties for the prototype fluid flow. 


$$
\begin{gathered}
\left(\frac{U_{f} \rho_{f} L}{\mu_{f}}\right)_{m} /\left(\frac{U_{f} \rho_{f} L}{\mu_{f}}\right)_{p}=\frac{U_{f, m}}{U_{f, p}} \frac{L_{m}}{L_{p}} \frac{\rho_{f, m}}{\rho_{f, p}} \frac{\mu_{f, p}}{\mu_{f, m}} \\
\frac{U_{f, m}}{U_{f, p}} \frac{\rho_{f, m}}{\rho_{f, p}} \frac{\mu_{f, p}}{\mu_{f, m}} \frac{L_{m}}{L_{p}}=1 \rightarrow \frac{U_{f, m}}{U_{f, p}}=\frac{\rho_{f, p}}{\rho_{f, m}} \frac{\mu_{f, m}}{\mu_{f, p}} \frac{L_{p}}{L_{m}} \\
U_{f, m}=\frac{\rho_{f, p}}{\rho_{f, m}} \frac{\mu_{f, m}}{\mu_{f, p}} \frac{L_{p}}{L_{m}} U_{f, p}
\end{gathered}
$$

The ratio of the length scales is defined as the geometric scaling factor, $f_{\text {scale }}$. Substituting that into Eq. 33 gives,

$$
U_{f, m}=\left(\frac{\rho_{f, p}}{\rho_{f, m}} \cdot \frac{\mu_{f, m}}{\mu_{f, p}} \cdot f_{\text {scale }}\right) U_{f, p}=C_{U} \cdot U_{f, p}
$$

where $C_{U}$ is the fluid velocity coefficient that is determined based on fluid properties andgeometric scale.

Similarly, from the Stoke relation, the particle diameter can be determined as,

$$
\left(\frac{\rho_{\text {part }} d_{\text {part }}^{2}}{18 \mu_{f}} \frac{U_{f}}{L}\right)_{m} /\left(\frac{\rho_{\text {part }} d_{\text {part }}^{2}}{18 \mu_{f}} \frac{U_{f}}{L}\right)_{p}=\frac{\rho_{\text {part }, m}}{\rho_{\text {part }, p}} \frac{\mu_{f, p}}{\mu_{f, m}} \frac{d_{p a r t, m}^{2}}{d_{p a r t, p}^{2}} \frac{L_{p}}{L_{m}} \frac{U_{f, m}}{U_{f, p}}
$$

Substituting Eq. 32, the ratio of the velocity scales, into Eq. 35 yields,

$$
\frac{\rho_{\text {part }, m}}{\rho_{\text {part }, p}} \frac{\rho_{f, p}}{\rho_{f, m}} \frac{d_{\text {part }, m}^{2}}{d_{\text {part }, p}^{2}}\left(\frac{L_{p}}{L_{m}}\right)^{2}=1
$$

The diameter of the particle in the model can be solved algebraically,

$$
\frac{\rho_{\text {part }, m}}{\rho_{\text {part }, p}} \frac{\rho_{f, p}}{\rho_{f, m}} \frac{d_{\text {part }, m}^{2}}{d_{\text {part }, p}^{2}}\left(\frac{L_{p}}{L_{m}}\right)^{2}=1 \rightarrow d_{\text {part }, m}=\left(\frac{L_{m}}{L_{p}} \sqrt{\frac{\rho_{\text {part }, p}}{\rho_{\text {part }, m}} \frac{\rho_{f, m}}{\rho_{f, p}}}\right) d_{\text {part }, p}
$$

Solving Eq. 36 gives the following simplified expression,

$$
d_{\text {part }, m}=\left(\frac{1}{f_{\text {scale }}} \sqrt{\frac{\rho_{\text {part }, p}}{\rho_{\text {part }, m}} \frac{\rho_{f, m}}{\rho_{f, p}}}\right) d_{\text {part }, p}=C_{d p} \cdot d_{\text {part }, p}
$$

where $C_{d p}$ is a particle diameter coefficient determined by fluid properties and geometric scale.

Different GFR fuels and designs will have different potential fission products and coolants. Using Eq. 33 and 37, fluid velocity and particle diameter of the scaled model can be modified to accommodate different coolants. For example, considering Helium as the primary coolant and graphite dust as the particle in the prototype, $U_{f, m}$ and $d_{p a r t, m}$ would be scaled accordingly to 
guarantee similarity between model and loop. Calculations of fluid velocity and particle diameter of the scaled model for different temperatures of Helium primary coolant are given in Table 5-1.

Table 5-1: Scaled Model Particle Diameter and Fluid Velocity

\begin{tabular}{|c|c|c|c|c|}
\hline $\boldsymbol{T}\left(_{\mathbf{o}} \mathbf{C}\right)$ & $\boldsymbol{C}_{\boldsymbol{d} \boldsymbol{p}}$ & $\boldsymbol{D}_{\text {part, } \boldsymbol{m}(\boldsymbol{\mu m})}$ & $\boldsymbol{C u}_{\boldsymbol{u}}$ & $\boldsymbol{U}_{\boldsymbol{f}, \boldsymbol{m}(\boldsymbol{m} / \boldsymbol{s})}$ \\
\hline 100.0 & 0.694 & 6.941 & 2.381 & 1.191 \\
\hline 200.0 & 0.782 & 7.816 & 1.596 & 0.798 \\
\hline 300.0 & 0.860 & 8.601 & 1.153 & 0.576 \\
\hline 400.0 & 0.932 & 9.321 & 0.880 & 0.440 \\
\hline 500.0 & 0.999 & 9.989 & 0.695 & 0.347 \\
\hline 600.00 & 1.062 & 10.616 & 0.565 & 0.282 \\
\hline
\end{tabular}

Serving as the model for preliminary testing, the proof-of-concept facility (see Chapter 7) will be operated under isothermal conditions $\left(20^{\circ} \mathrm{C}\right)$ at atmospheric pressure using air. As a starting point, Helium and graphite dust properties are assumed for the loop and applied to the scaling for the proof-of-concept facility.

A list of potential fission products from GFR CL (private communication with GA) is shown in Table 5-2. Details of items listed in this table are provided below.

- Particle diameter refers to the diameter of the absorbent material in the high temperature absorber, which is assumed to be activated carbon.

- Helium is the carrier gas resulting from leakage through the fuel element cladding from pin holes and cracks. GA's analysis allows for a large number of microcracks developing over time. The design leakage flow rate into the fuel elements is $1 \mathrm{~kg} / \mathrm{s}$ of He. The fission products constitute a very small partially pressure as shown in the first row of the Table.

- The volumetric flow is the flow of helium plus fission product gases. The flow of helium is the dominant constituent so that the numbers are constant.

- The friction factor is calculated as the particle bed friction factor. 
Table 5-2: GA Fission Products and High Temperature Absorber (HTA) Properties

\begin{tabular}{|c|c|c|c|c|c|c|c|c|c|c|}
\hline & Tritium & Bromine & Krypton & Rubidium & Strontium & Tellurium & Iodine & Xenon & Cesium & Barium \\
\hline $\begin{array}{l}\text { Temp. indep. const. } \\
(\mathrm{mol} / \mathrm{g}-\mathrm{Pa})\end{array}$ & & $5.05 \mathrm{E}-06$ & $5.05 \mathrm{E}-06$ & $5.05 \mathrm{E}-06$ & $5.05 \mathrm{E}-06$ & $5.05 \mathrm{E}-06$ & $5.05 \mathrm{E}-06$ & $6.10 \mathrm{E}-12$ & $5.05 \mathrm{E}-06$ & $5.05 \mathrm{E}-06$ \\
\hline $\begin{array}{l}\text { Isoteric heat of adsop. } \\
(\mathrm{J} / \mathrm{mol})\end{array}$ & & -22000 & -22000 & -22000 & -28000 & -28000 & -28000 & -28000 & -28000 & -28000 \\
\hline Temperature (C) & 188 & 188 & 188 & 188 & 189 & 188 & 188 & 188 & 188 & 188 \\
\hline Volume flow (m3/s) & 0.073 & 0.073 & 0.073 & 0.073 & 0.073 & 0.073 & 0.073 & 0.073 & 0.073 & 0.073 \\
\hline $\begin{array}{c}\text { Moles of element } \\
(\mathrm{mol} / \mathrm{g})\end{array}$ & & $1.57 \mathrm{E}-03$ & $8.36 \mathrm{E}-11$ & $1.57 \mathrm{E}-03$ & $3.38 \mathrm{E}-03$ & $7.52 \mathrm{E}-03$ & $7.52 \mathrm{E}-03$ & $7.52 \mathrm{E}-03$ & $7.52 \mathrm{E}-03$ & $7.52 \mathrm{E}-03$ \\
\hline $\begin{array}{l}\text { Superficial velocity } \\
(\mathrm{m} / \mathrm{s})\end{array}$ & 0.094 & 0.094 & 0.094 & 0.094 & 0.094 & 0.094 & 0.094 & 0.094 & 0.094 & 0.094 \\
\hline Particle diameter $(\mathrm{m})$ & 0.003 & 0.003 & 0.003 & 0.003 & 0.003 & 0.003 & 0.003 & 0.003 & 0.003 & 0.003 \\
\hline $\begin{array}{l}\text { Bed bulk density } \\
(\mathrm{kg} / \mathrm{m} 3)\end{array}$ & 400 & 400 & 400 & 400 & 400 & 400 & 400 & 400 & 400 & 400 \\
\hline Bed packing fraction & 0.7 & 0.7 & 0.7 & 0.7 & 0.7 & 0.7 & 0.7 & 0.7 & 0.7 & 0.7 \\
\hline Bed outer diameter $(\mathrm{m})$ & 1 & 1 & 1 & 1 & 1 & 1 & 1 & 1 & 1 & 1 \\
\hline Bed inner diameter $(\mathrm{m})$ & 0.2 & 0.2 & 0.2 & 0.2 & 0.2 & 0.2 & 0.2 & 0.2 & 0.2 & 0.2 \\
\hline Bed depth $(\mathrm{m})$ & 1.75 & 1.75 & 1.75 & 1.75 & 1.75 & 1.75 & 1.75 & 1.75 & 1.75 & 1.75 \\
\hline Bed volume (m3) & 1.319 & 1.319 & 1.319 & 1.319 & 1.319 & 1.319 & 1.319 & 1.319 & 1.319 & 1.319 \\
\hline Total adsorbent mass & 527.8 & 527.8 & 527.8 & 527.8 & 527.8 & 527.8 & 527.8 & 527.8 & 527.8 & 527.8 \\
\hline $\begin{array}{c}\text { Helium mass flow } \\
(\mathrm{kg} / \mathrm{s})\end{array}$ & 1 & 1 & 1 & 1 & 1 & 1 & 1 & 1 & 1 & 1 \\
\hline Helium pressure $(\mathrm{Pa})$ & $\begin{array}{c}1.31 \mathrm{E}+0 \\
7\end{array}$ & $1.31 \mathrm{E}+07$ & $1.31 \mathrm{E}+07$ & $1.31 \mathrm{E}+07$ & $1.31 \mathrm{E}+07$ & $1.31 \mathrm{E}+07$ & $1.31 \mathrm{E}+07$ & $1.31 \mathrm{E}+07$ & $1.31 \mathrm{E}+07$ & $1.31 \mathrm{E}+07$ \\
\hline $\begin{array}{l}\text { Helium viscosity (N- } \\
\text { s/m2) }\end{array}$ & $\begin{array}{c}2.43 \mathrm{E}- \\
05 \\
\end{array}$ & $2.43 \mathrm{E}-05$ & $2.43 \mathrm{E}-05$ & $2.43 \mathrm{E}-05$ & $2.43 \mathrm{E}-05$ & $2.43 \mathrm{E}-05$ & $2.43 \mathrm{E}-05$ & $2.43 \mathrm{E}-05$ & $2.43 \mathrm{E}-05$ & $2.43 \mathrm{E}-05$ \\
\hline Helium density $(\mathrm{kg} / \mathrm{m} 3)$ & 13.68 & 13.68 & 13.68 & 13.68 & 13.68 & 13.68 & 13.68 & 13.68 & 13.68 & 13.68 \\
\hline Reynolds number & 228 & 228 & 228 & 228 & 228 & 228 & 228 & 228 & 228 & 228 \\
\hline Friction factor & 2.41 & 2.41 & 2.41 & 2.41 & 2.41 & 2.41 & 2.41 & 2.41 & 2.41 & 2.41 \\
\hline Pressure drop (psid) & 0.64 & 0.64 & 0.64 & 0.64 & 0.64 & 0.64 & 0.64 & 0.64 & 0.64 & 0.64 \\
\hline Gas Constant $(\mathrm{J} / \mathrm{mol}-\mathrm{K})$ & 8.314 & 8.314 & 8.314 & 8.314 & 8.314 & & & & & \\
\hline
\end{tabular}




\section{OVERVIEW OF THE PROOF-OF-CONCEPT TEST FACILITY}

The development and implementation of instrumentation and measurement techniques to characterize transport and dynamics of surrogate particles will be applied to the proof-of-concept facility (channel) prior to applying them to the Primary System and FPVS of the simplified GFR Cartridge Loop. Experimental measurements performed on the proof-of-concept facility will allow the verification of scaling approaches developed for the surrogate particles and the performances of carbon nanotube (CNT) materials in filtering and trapping particles.

A proof-of-concept facility was designed to operate either vertically or horizontally to mimic flows in the FPVS of GFR Cartridge Loop.

Figure 6-1 shows a photo and the design of the proof-of-concept facility. The test facility is a square cross-sectional channel with $76.2 \mathrm{~mm}$ ( 3 in) side lengths, and has three parts, each 609.6 $\mathrm{mm}(24 \mathrm{in})$ long for a combined total length of $1,828.8 \mathrm{~mm}$ (72 in). While the first part of the facility is used for flow development, the third part prevents backflow and provides additional space for particle filtration from air to avoid exposure. The middle, i.e., test, section has a removable surface plate to allow surface modification for particle deposition measurement.
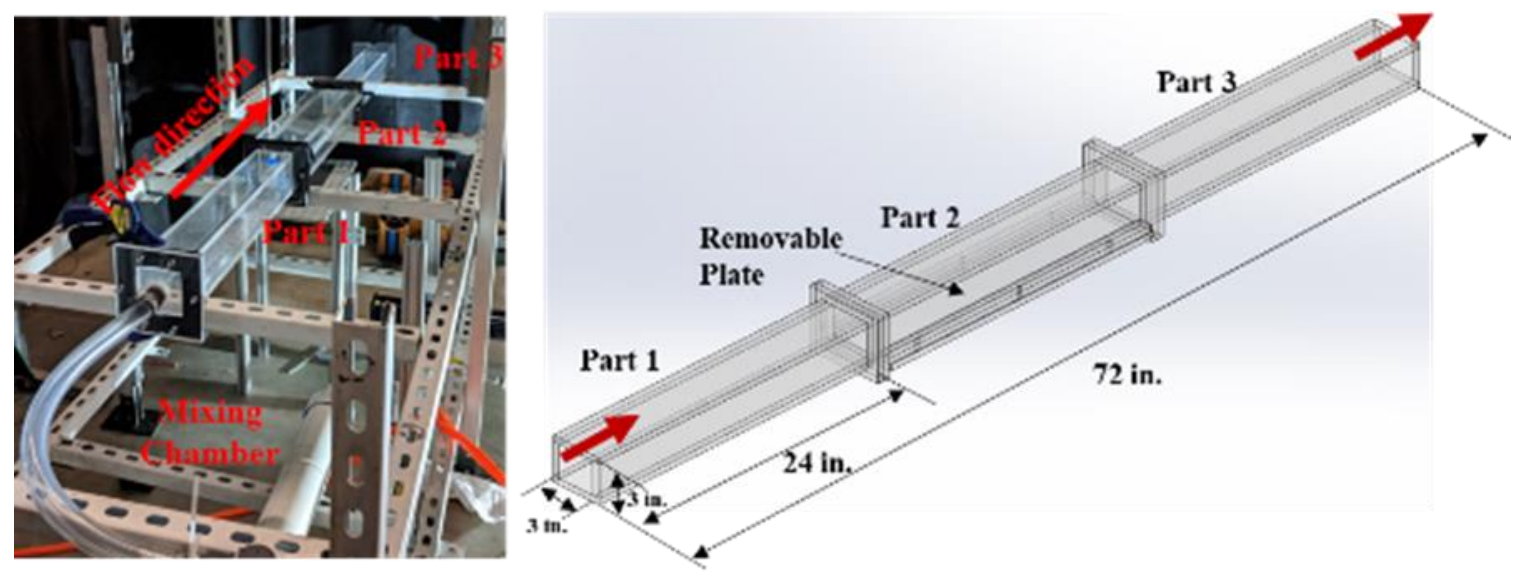

Figure 6-1. Proof-of-concept test facility and computer-assisted drawing (CAD) of the facility.

The facility is connected to an air compressor, with maximum pressure of $1.2 \mathrm{MPa}$ to allow the adjustment of air-flow rates. The fluid is passed through a mixing chamber where the fluid-particle mixture can be created prior to entering the inlet of the test facility. A hot-wire anemometer is used to measure upstream velocity and determine the volumetric flow rate of the mixture. In this report, two types of surrogate particles were selected, including aerosol droplets and solid particles. The aerosol droplets were generated from Di-Ethyl-Hexyl-Sebacate liquid and had a mean diameter of $1 \mu \mathrm{m}$ and a density of $910 \mathrm{~kg} / \mathrm{m} 3$. The solid particles were prepared from dry expanded microspheres with a mean diameter in between $25-50 \mu \mathrm{m}$ and a density of $42 \mathrm{~kg} / \mathrm{m} 3$. For the tests considered in this report, the Stoke numbers estimated for the surrogate particles are found $S t k_{\text {part }} \ll 1$ to ensure that the particles will follow the fluid flow. If an appropriate concentration of surrogate particles is premixed in the mixing chamber and released into the test facility, the aerodynamics of particle-air mixture and transport of surrogate particles within the proof-ofconcept facility can be characterized simultaneously by applying a laser-diagnostics techniques, such as particle-image velocimetry (PIV) or particle-tracking velocimetry (PTV). These laserdiagnostic techniques are non-intrusive and able to acquire both fluid flow velocity and dynamic 
behavior of surrogate particles such as velocity, size, spatial distribution and concentration within the test facility. Because the test facility is built using transparent materials, once the fluid mixture enters the test section of the test facility, optical measurement techniques, including PIV and PTV, are applied to characterize the flow fields within the test section. Details on implementation of the PIV and PTV systems to characterize the aerodynamic flow fields and surrogate particle transports in the proof-of-concept facility will be provided in Chapter 8. 


\section{INSTRUMENTATION}

The high-power lasers are a crucial part of applying a multitude of measurement techniques. Three lasers are used simultaneously. The first is a solid-state continuous $532 \pm 1 \mathrm{~nm}$ green laser (Model MGL-W-532-20W, see Figure 7-1). This laser is used to illuminate the inlet and outlet of the test facility.

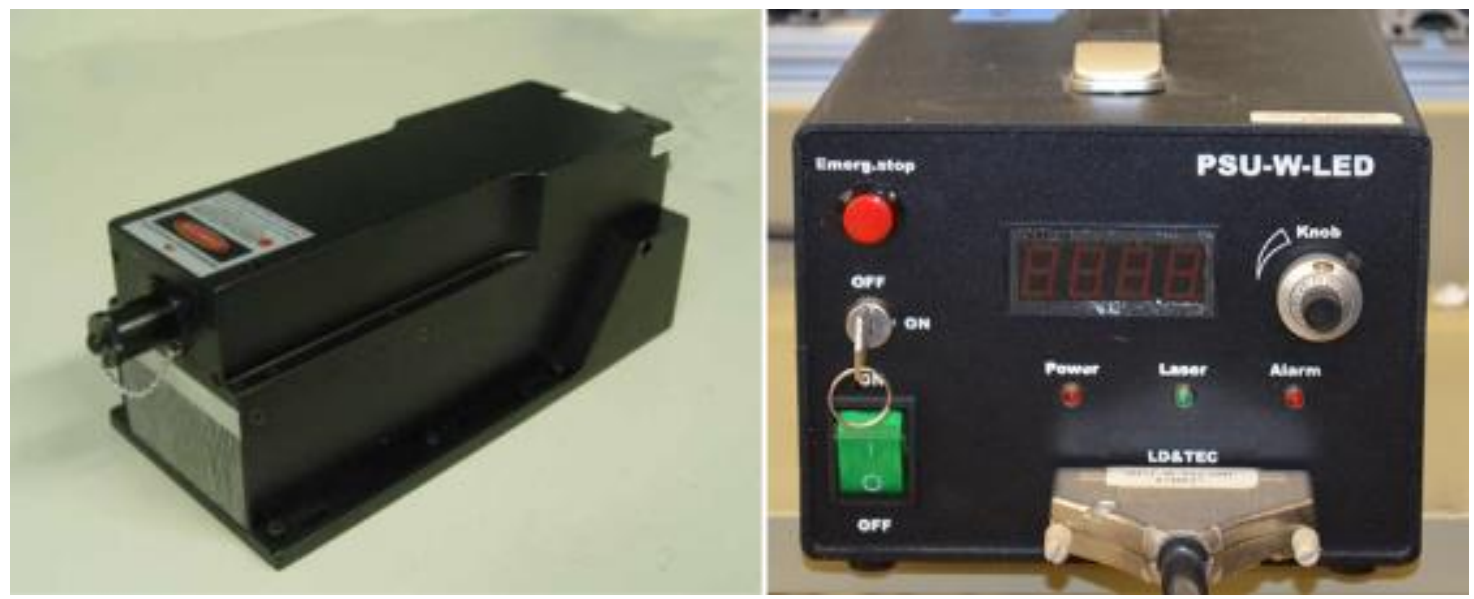

Figure 7-1. Left: continuous 532-nm laser and right: adjustable power supply.

The second laser is a dual pulse $532 \pm 1 \mathrm{~nm}$ green laser (VLite-200 Series) (Figure 7-2). The dual pulse laser will be used to create a laser sheet in the center of the test facility.
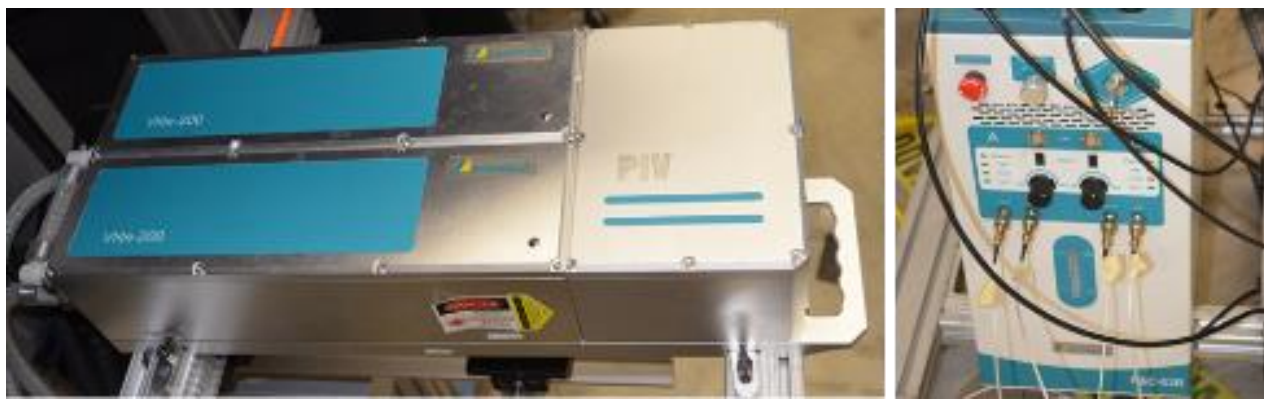

Figure 7-2. Left: pulse $532 \mathrm{~nm}$ laser and right: adjustable power and frequency.

The third laser is a low-power $532 \pm 1 \mathrm{~nm}$ green laser (see Figure 7-3). This low-power laser will be used to illuminate the wall of the test facility. 


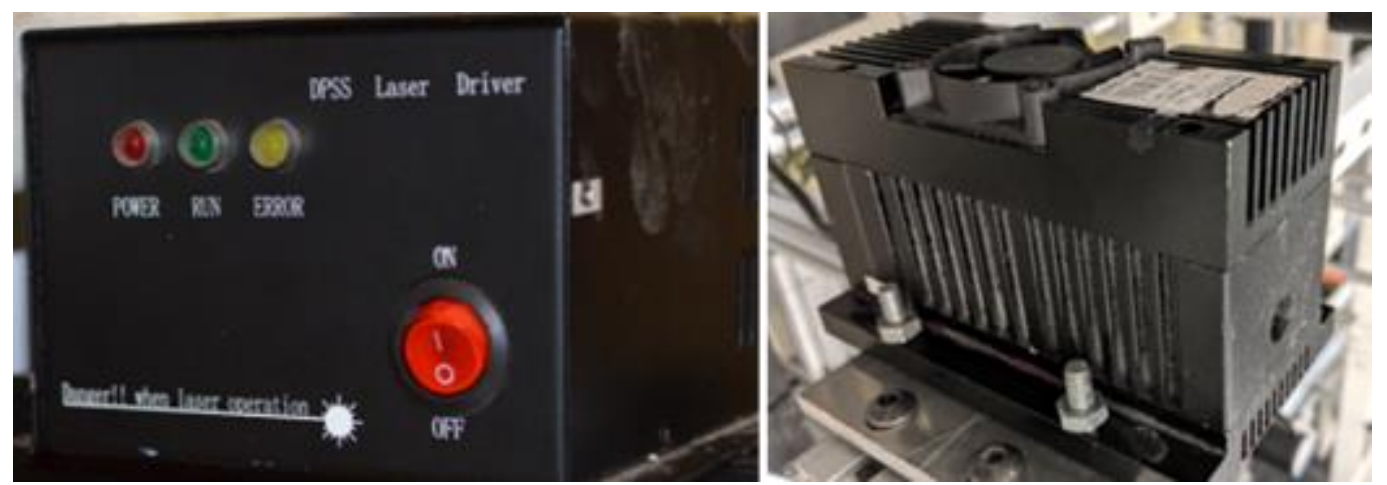

Figure 7-3. Left: solid-state $532 \mathrm{~nm}$ laser and right: power supply.

High-resolution cameras will be used in parallel with the laser to capture images. Two double exposure IMPERX Bobcat series charged couple device (CCD) cameras, shown in Figure 7-4, and two MEMRECAM GX-3 high-speed cameras (see Figure 7-5) are operated during the test.
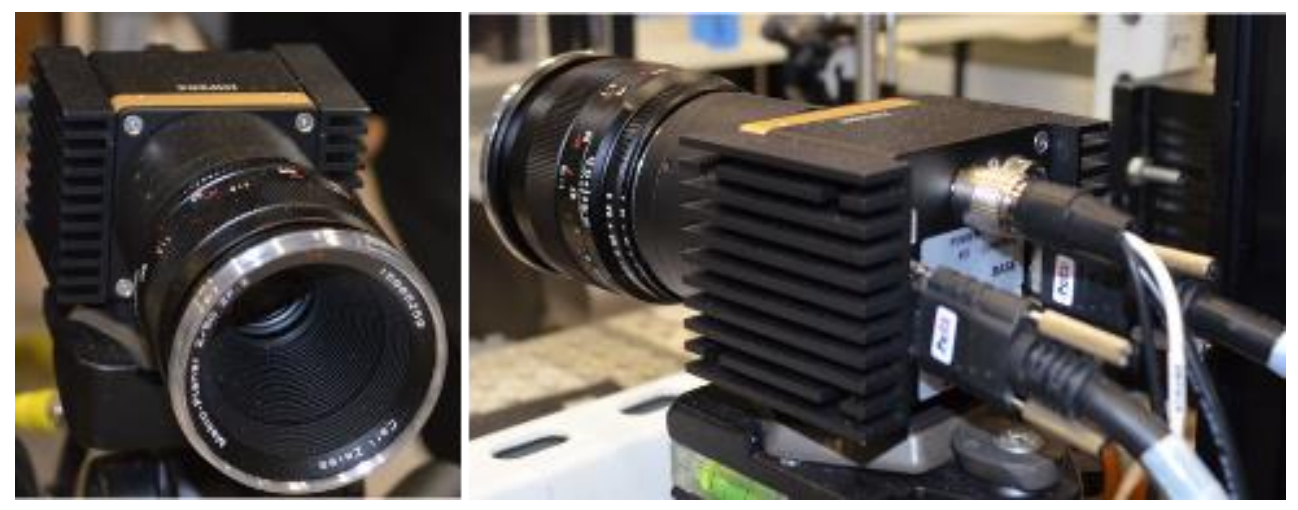

Figure 7-4. Left: A 4-megapixel and right: an 8-megapixel camera.

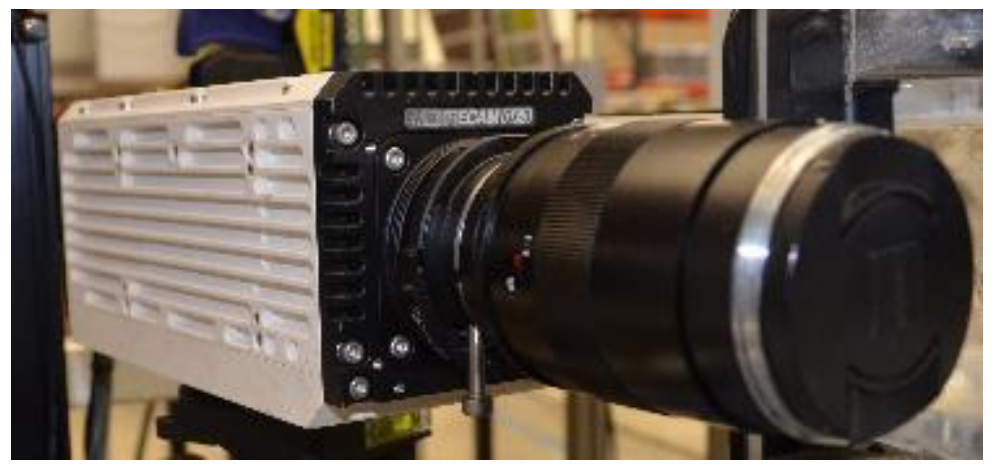

Figure 7-5. High-speed 1.3-megapixel camera.

The high- resolution cameras used to capture images near the wall is equipped with a highmagnification lens and coaxial illumination port (Model MVL6X3Z) for improved lighting (see Figure 7-6). 

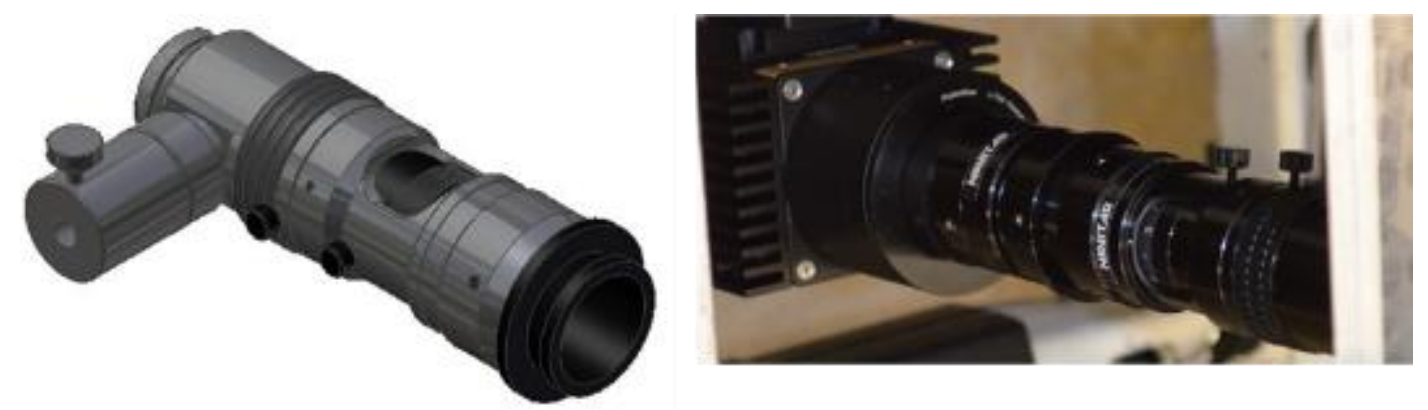

Figure 7-6. High-magnification lens for capturing particle deposition in the near-wall region.

The seeding particles are injected via a TSI six-jet atomizer (Model 9306) or mixing chamber, depending on the particle of choice, such as aerosol droplets (Di-Ethyl-Hexyl-Sebacate droplets) and solid particles (dry expanded microspheres), as shown in Figure 7-7.

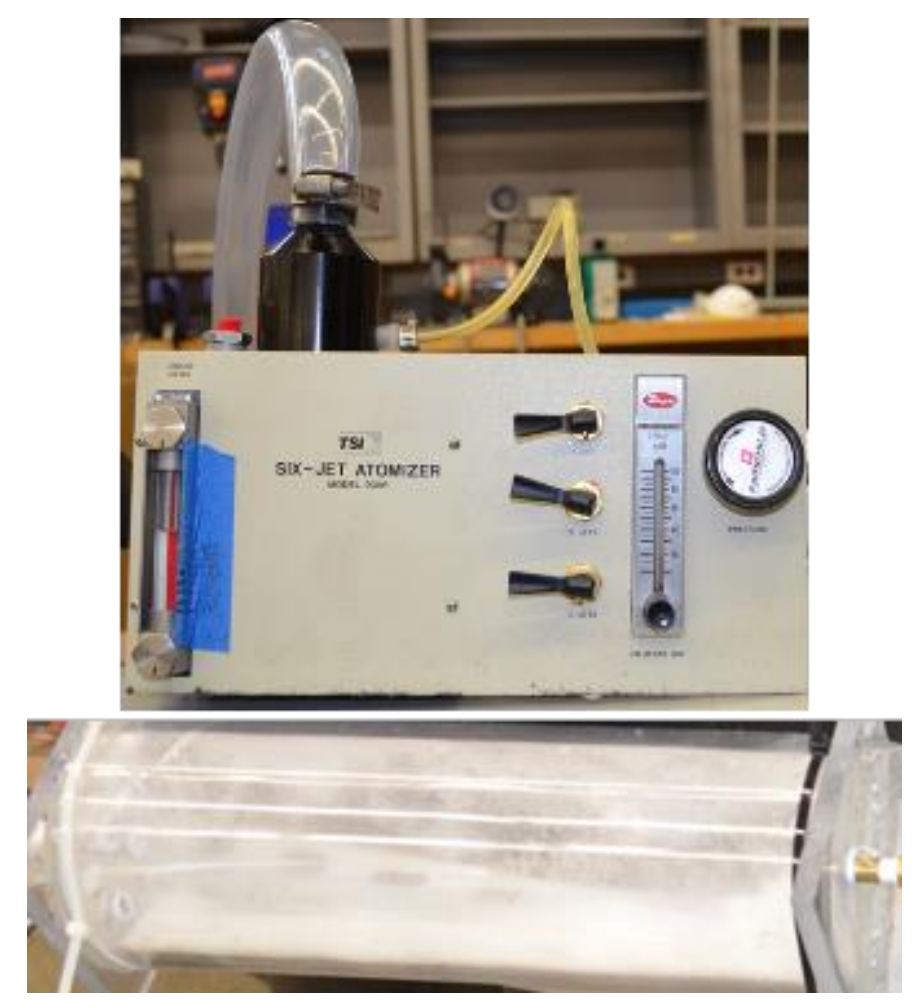

Figure 7-7. Top: Six-jet oil atomizer and bottom: solid-particle reservoir.

Air pressure is control by an Ingersoll Rand compressor (Model CBV497386) with pressure gauges, and the air flow rate is verified using a TSI air-velocity meter (Model 9535). Both are shown in Figure 7-8. 


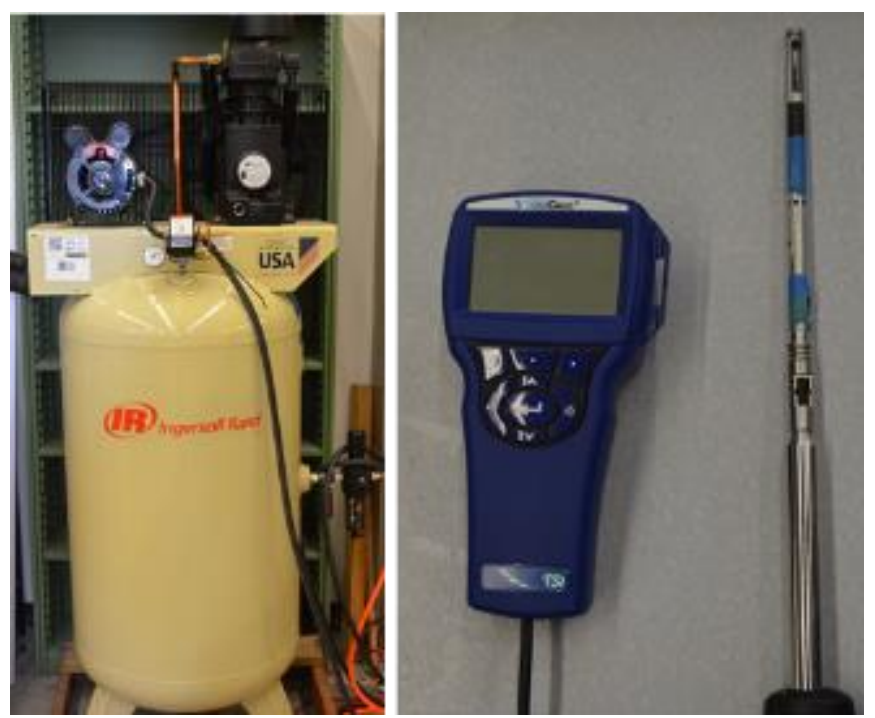

Figure 7-8. Left: air compressor and right: anemometer. 


\section{METHODOLOGY}

This section describes non-intrusive optical experimental techniques, PIV and PTV, that are applied to acquire the aerodynamic flow fields and characteristics of surrogate particles within the proof-of-concept facility.

PIV and PTV are non-intrusive, laser-based, optical measurement techniques that quantify the displacement of fluid elements (Raffel et al., 2007). This displacement is captured by using highly reflective, low-density micro seeding particles that follow the fluid flow without impacting flow characteristics. A laser sheet is used to illuminate the test section, and tracer particles scatter laser light as they pass through the laser sheets at the regions of interest. A series of images are captured using digital cameras at a desired frequency. For PIV measurements, the acquired experimental images are discretized into sub-regions, and particle displacements are estimated at regular grids based on the calculations of cross-correlation between two successive images. PTV relies on the direct tracking of individual particles between successive images. This Lagrangian approach enables the simultaneous acquisition of sizes, spatial locations, and displacements of various types of particles (Peurrung et al., 1995), i.e., in this study, surrogate particles dispersed in the fluid flow.

Figure 8.1-1 shows the experimental configuration of the proof-of-concept test facility with experimental setups for PIV and PTV systems to quantify the aerodynamic flow fields and surrogate particle transport within the test section. It is noted that the aerodynamic flows fields are acquired using PIV technique and aerosol droplets as seeding, while the surrogate particle transport is studied using PTV technique and solid particles were injected into the test section.

\subsection{AERODYNAMIC FLOW MEASUREMENTS IN THE PROOF-OF- CONCEPT FACILITY USING AEROSOL DROPLETS AND PIV TECHNIQUE}

To acquire aerodynamic flow fields in the proof-of-concept facility, two-dimensional twocomponent (2D2C) PIV measurements are performed. For the current PIV measurements, the measured flow area is illuminated by the laser sheet and located at the center plane of the test section, as shown in Figure 8.1-1. The origin of the coordinate system was at the inlet and along the center plane of the test section, in which $x$ - and $y$-directions are the streamwise and wall-normal directions. The velocity components corresponding to the $x$ and $y$ directions were $U$ and $V$ for timeaveraged velocities, and $u^{\prime}$ and $v^{\prime}$ for fluctuating velocities, respectively. The 2D2C PIV system consisted of a dual-head neodymium-doped yttrium aluminum garnet (Nd:YAG) laser, a digital CCD camera, a synchronizer, and a computer. Each laser beam of the double-pulsed laser was capable of $200 \mathrm{~mJ}$ at a wavelength of $532 \mathrm{~nm}$. These beams were adjusted by using an optical system of cylindrical and spherical lenses to form a 1-mm-thick laser sheet. For the 2D2C PIV measurements, out-of-plane particle displacements could make the loss of pairs significant, which could strongly reduce correlation peaks computed from image cross-correlation calculations, and then reduce the possibility of searching a valid peak from the correlation map. To mitigate this difficulty, the suggestions of Raffel et al. (2007) were used to choose an appropriate laser-sheet thickness and the time interval between the image recordings to accommodate out-of-plane displacement of particles. The laser-sheet thickness of $1 \mathrm{~mm}$ was therefore optimized to be thin enough to guarantee an adequate particle-image intensity, but thick enough to reduce the loss of image pairs due to out-of-plane particle displacements. For each studied Reynolds number, a collection of 1,500 pairs of PIV double-pulsed images were acquired using the CCD 4MP camera, which had a maximum resolution of $2336 \times 1752$ and a pixel size of $5.5 \times 5.5 \mu \mathrm{m} 2$ at a sampling 
rate of $10 \mathrm{~Hz}$. The Zeiss camera lens had a $105-\mathrm{mm}$ focal length and an f/5.6 aperture. An aerosoldroplet generator was used with Di-Ethyl-Hexyl-Sebacate (DEHS) liquid that generates particles with a mean diameter of $1 \mu \mathrm{m}$ to seed the inlet. A time interval between the first- and secondimage exposures was $500 \mu \mathrm{s}$, yielding a maximum particle displacement of 10 pixels. Experimental images are processed using in-house codes, featuring the advanced multi-pass, multigrid robust phase correlation (RPC) algorithms (Eckstein \& Vlachos, 2009). PIV imageprocessing had four iterations, which start from $128 \times 64$ pixels and ended at $32 \times 16$ pixels. Particle displacements initially calculated from the previous iteration were used to shift the interrogation window in the next iteration. All PIV iterations had a 50\% window overlap, yielding the final spatial gap between two adjacent vectors of $0.73 \mathrm{~mm}$. In all the PIV iterations, particle displacements were computed from the correlation map with a Gaussian-peak fit for subpixel accuracy (Raffel, et al., 2007). Within each iteration, statistical validations were performed to identify and replace erroneous vectors. A median filter (Westerweel, 1994), based on the standard deviations of the neighboring vectors, is used to filter out spurious vectors. The resultant blanks were then filled by velocity interpolation.

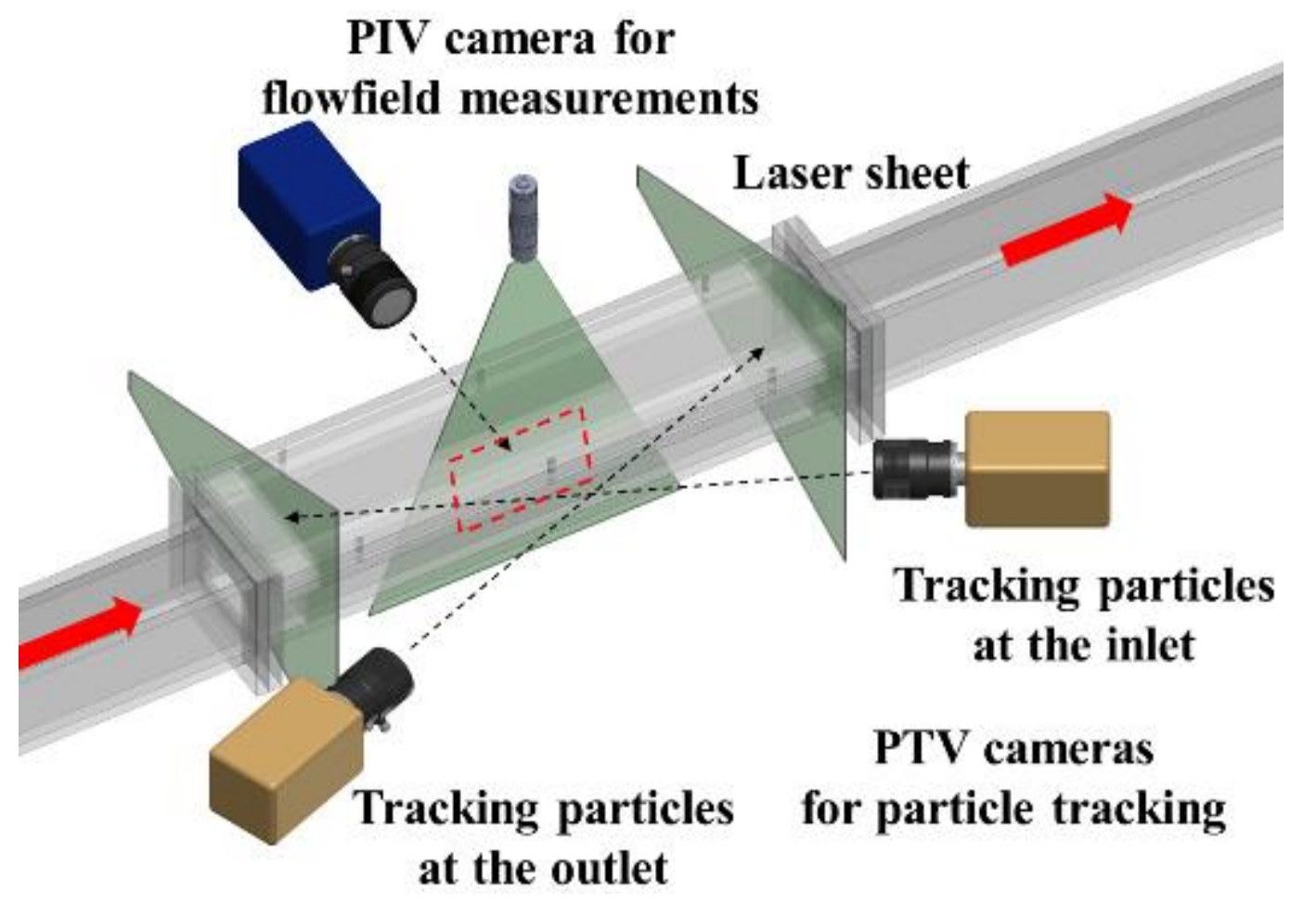

Figure 8.1-1. PIV and PTV schematics.

\subsection{PARTICLE TRANSPORT IN THE PROOF-OF-CONCEPT FACILITY USING SURROGATE PARTICLES AND PTV TECHNIQUE}

To study particle transport in the test section of the proof-of-concept facility, surrogate particles prepared from dry expanded microspheres that have low density of $42 \mathrm{~kg} / \mathrm{m} 3$ are used. The particle size, $d_{\text {part }, m}$, given by the manufacturer is $25-50 \mu \mathrm{m}$. The system has a built-in pressure regulator and pressure gauge, as well as a dilution system to reduce the particle 
concentration when needed. External valves allow for both the particle concentration and the total particle output to be adjusted. The system can be used to generate varied particle-air mixture.

To allow for particle-deposition measurement near the wall region, the solid microsphere particles described are dyed with Rhodamine-6G (having an absorption peak at $532 \mathrm{~nm}$ and an emission peak at $552 \mathrm{~nm}$ ). The chemical compound moves to an excited energy state when it absorbs $532 \mathrm{~nm}$ light, which is identical to the laser light used during experiments. Rhodamine6G then fluoresces at $552 \mathrm{~nm}$ allowing for laser-induced fluorescence (LIF) measurement technique to be implemented (Northrup, et al., 1991). This fluorescent dye was selected due to its negligible response to temperature changes; this makes it suitable for concentration measurement. Figure 8.1-2 shows the solid particles before and after being dyed with the tracer dye in the laboratory.

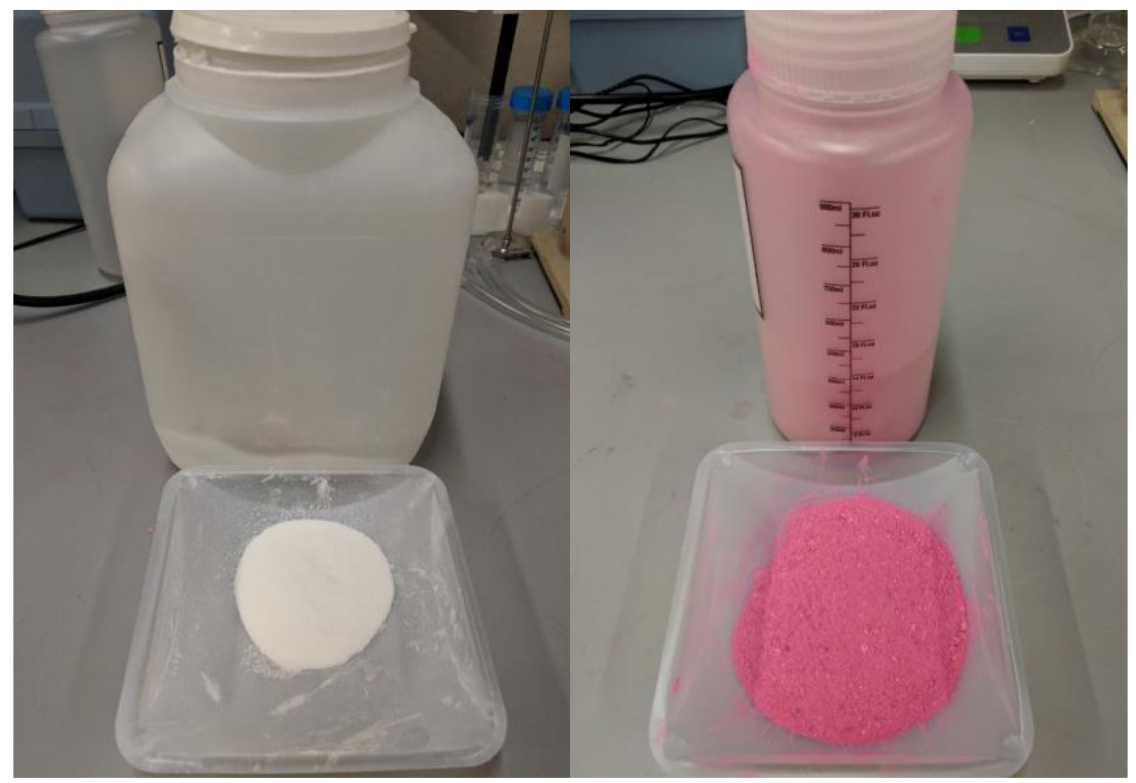

Figure 8.1-2. Left: original, undyed solid particles and right: particles dyed in the laboratory.

It has also been proposed that the use of Carbon nanotube (CNT) could affect particle penetration and, potentially, increase filtration (Yildiz \& Bradford, 2013; Salvetat, et al., 1999). CNT-coated surfaces can potentially alter surface properties to attract and capture fission products. The current proof-of-concept test facility will be employed to characterize the performance of CNT on particle deposition. For this purpose, experimental measurements will be performed in the test section of the proof-of-concept facility with its bottom wall coated with CNT materials. Figure 8.1-3 shows the structure of these CNT materials at the micro scale. 

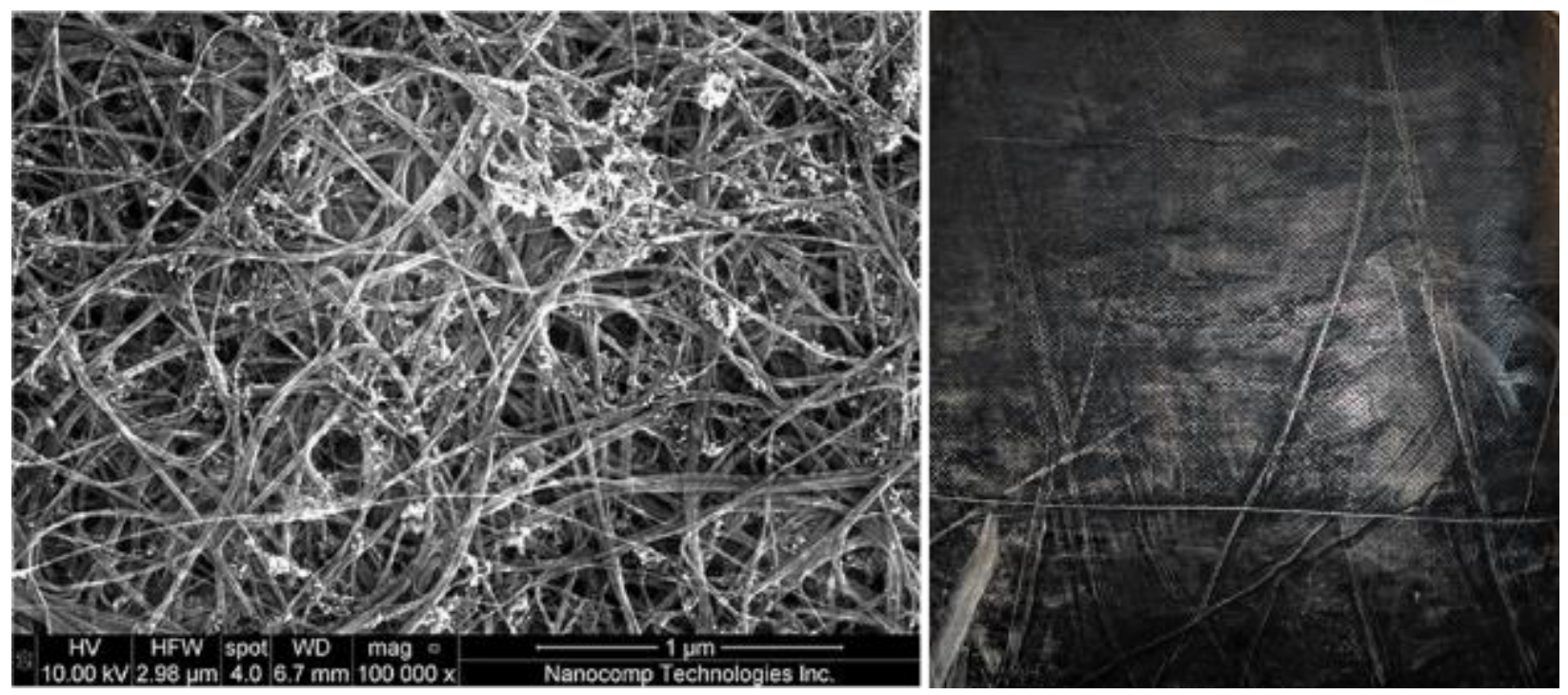

Figure 8.1-3. (Left): high-magnification image of CNT (Right): Full CNT sheet provided by Nanocomp Technologies, Inc.

It is important to note that before applying the CNT sheet to the simplified GFR Cartridge Loop FPVS facilities, tests will be conducted on the PCF with and without surface modification to adequately observe the effects of CNT on surrogate particles.

The sophisticated systems of combined PIV and PTV techniques enable investigations of particle transport and deposition as a function of turbulence characteristics. It has been shown in previous research that in low-turbulence fields, gravity will be the driving force for particle deposition, but in highly turbulent flows, a phenomenon known as turbophoresis will be the driving mechanism (Young \& Leeming, 1997). In order to study particle penetration through the midsection of the proof-of-concept channel, the total numbers of particles entering and exiting the test section are monitored by two PTV systems, installed at the inlet and outlet of the section (see Figure 8.1-1). 


\section{PRELIMINARY RESULTS}

\subsection{RESULTS OF AERODYNAMIC FLOW MEASUREMENTS IN THE PROOF-OF-CONCEPT FACILITY USING AEROSOL DROPLETS AND PIV TECHNIQUE}

In order to acquire flow-inlet conditions, the horizontal channel is injected with aerosol droplets, prior to solid particles, of about $1 \mu \mathrm{m}$ using a six-jet atomizer to generate an aerosol in high concentrations to be used as seeding particles for PIV measurements. The time-averaged inlet velocity over the duration of $150 \mathrm{~s}$ is shown at the left of Figure 9-1. A vertical-line profile for the velocity profile was selected for use in the boundary conditions in a parallel numerical study presented to the right of Figure 10-1. The images were post processed by calculating the mean background intensity of the image set and subtracting it from each image to reduce noise from scattered laser light and reflection. A static mask was then applied to define the channel height for analysis. It is presumed that measured displacement is related to the cross-correlation peak ratio in the correlation plane. The mean velocities have an estimated uncertainty less than $2 \%$. Uncertainty estimations of PIV velocity measurements are derived from the proposed methodologies discussed in studies of Moffat (1988) and Sciacchitano et al. (2015).

Experiments were conducted at three different Reynolds numbers $(3,187,4,534$, and 5,077). The Reynolds number is based on the bulk mean velocity, $U_{m e a n}$, the density, $\rho a i r$, and dynamic viscosity of air, $\mu$ air, and the hydraulic diameter of the channel, $D_{H}$. The values for these parameters can be found in Table 9-1 and Table 9-2. The studied Reynolds numbers were selected to be within the range of fluid velocity given in Table 5-1.

Table 9-1. Constant parameters used to calculate Reynolds number.

\begin{tabular}{|c|c|c|}
\hline $\boldsymbol{\rho}_{\text {air }}(\mathrm{kg} / \mathrm{m} 3)$ & $\boldsymbol{\mu}$ air $(\mathrm{kg} / \mathrm{m} \cdot \mathbf{s})$ & $\boldsymbol{D}_{\boldsymbol{H}}(\mathbf{m})$ \\
\hline 1.204 & $1.825 \times 10-5$ & 0.0762 \\
\hline
\end{tabular}

Table 9-2. Fluid flow rates and Reynolds number.

\begin{tabular}{|c|c|c|}
\hline$U_{\text {mean }}(\boldsymbol{m} / \mathbf{s})$ & $\boldsymbol{Q}(\mathbf{m} 3 / \mathbf{s})$ & $\boldsymbol{R e}$ \\
\hline 0.634 & 0.00368 & 3,187 \\
\hline 0.902 & 0.00524 & 4,534 \\
\hline 1.01 & 0.00586 & 5,077 \\
\hline
\end{tabular}

For the purpose of this report, the highest Reynolds will be presented for the analyses because it represents the most-turbulent flow. However, a full test has been performed for Reynold numbers listed in Table 9-2 and are analyzed using the PTV technique. 

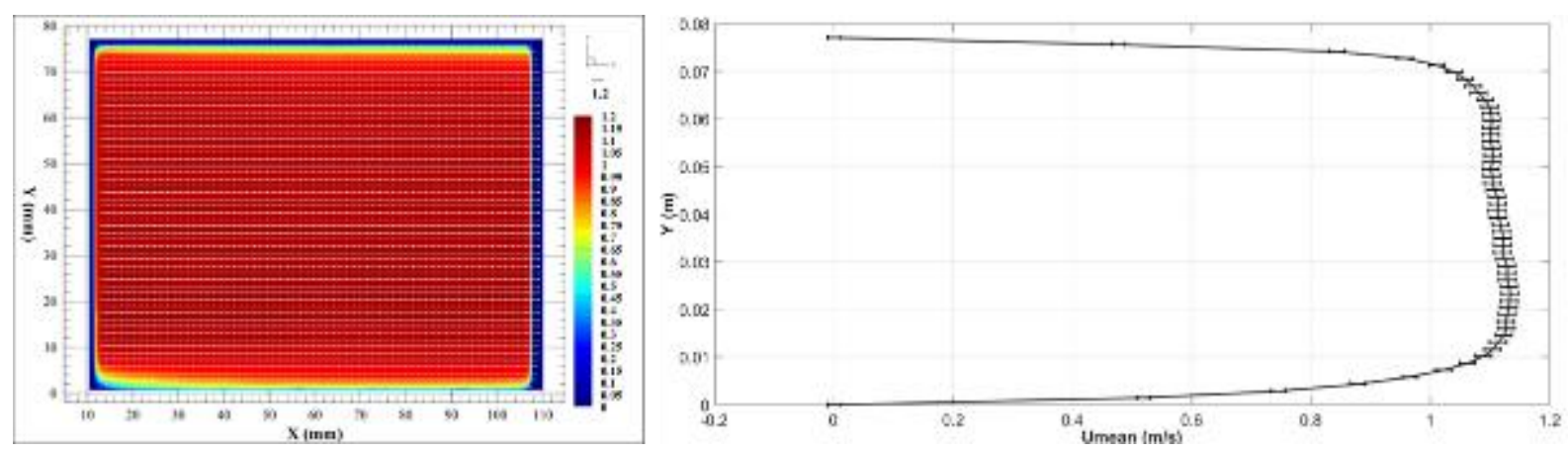

Figure 9-1. $\operatorname{Re}=5,077$. (Left): Mean velocity vector field and velocity magnitude contour. (Right): Profile of mean streamwise velocity, $U$, in the inlet section.

In addition to the full view of the test facility, measurements were conducted in a region near the bottom wall to aid in flow characterization.
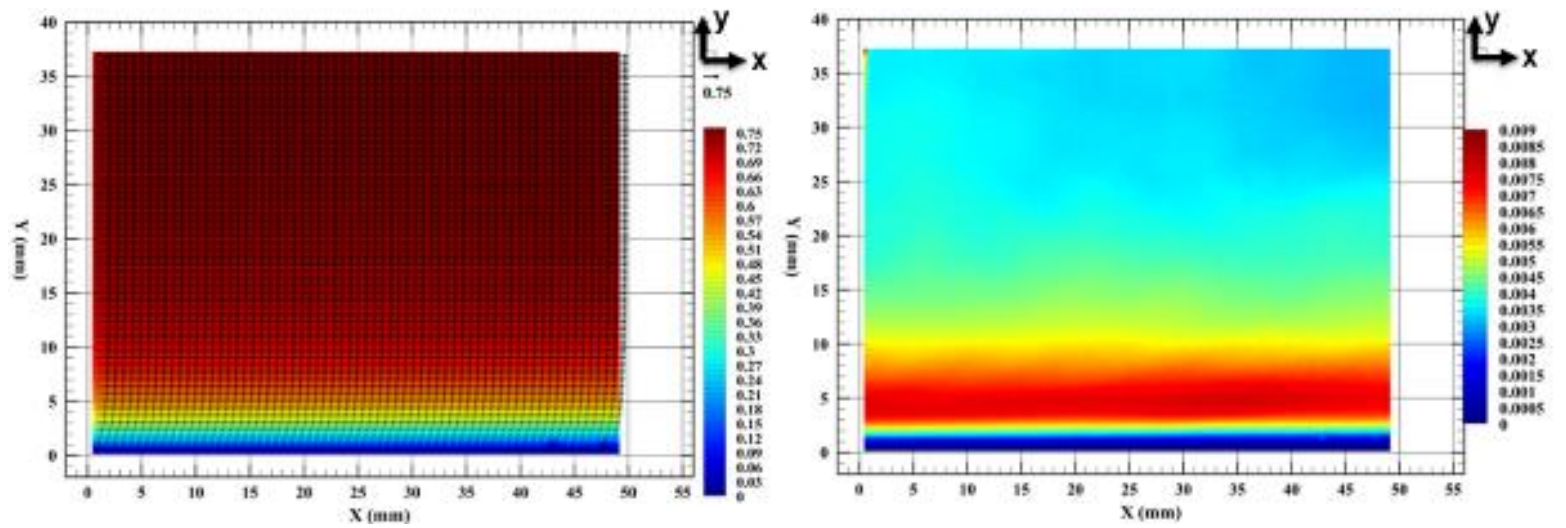

Figure 9-2. $\operatorname{Re}=5,077$. Flowfield measurements at the same axial location in Figure 9-1 with focus to the region near the bottom wall, i.e, $y=0$. Left: mean velocity vector field and color contour of velocity magnitude. Right: turbulent kinetic energy contour.

\subsection{RESULTS OF PARTICLE TRANSPORTS IN THE PROOF-OF- CONCEPT TEST FACILITY USING SURROGATE PARTICLES AND PTV TECHNIQUE}

Once the fluid flow field was characterized using the PIV method, transport of surrogate particles in the proof-of-concept facility was performed using the PTV method. This preliminary test ensures that the particles can be accurately characterized at the section inlet and outlet, as well as in the middle of test section. The particles had a density of $42 \mathrm{~kg} / \mathrm{m} 3$, and they were pre-mixed in a chamber prior to injection to have a uniform distribution. Independent measurements of the fluid flow were performed using a hot-wire anemometer to compare with the PIV and PTV results as an experimental reference and cross-check.

Figure 9-3 (left) shows the instantaneous velocity vectors calculated for all the particles in frame. Figure 9-3 (right) represents the particle size distribution for all frames captured. The particles counted are over a time interval of 50 seconds. 

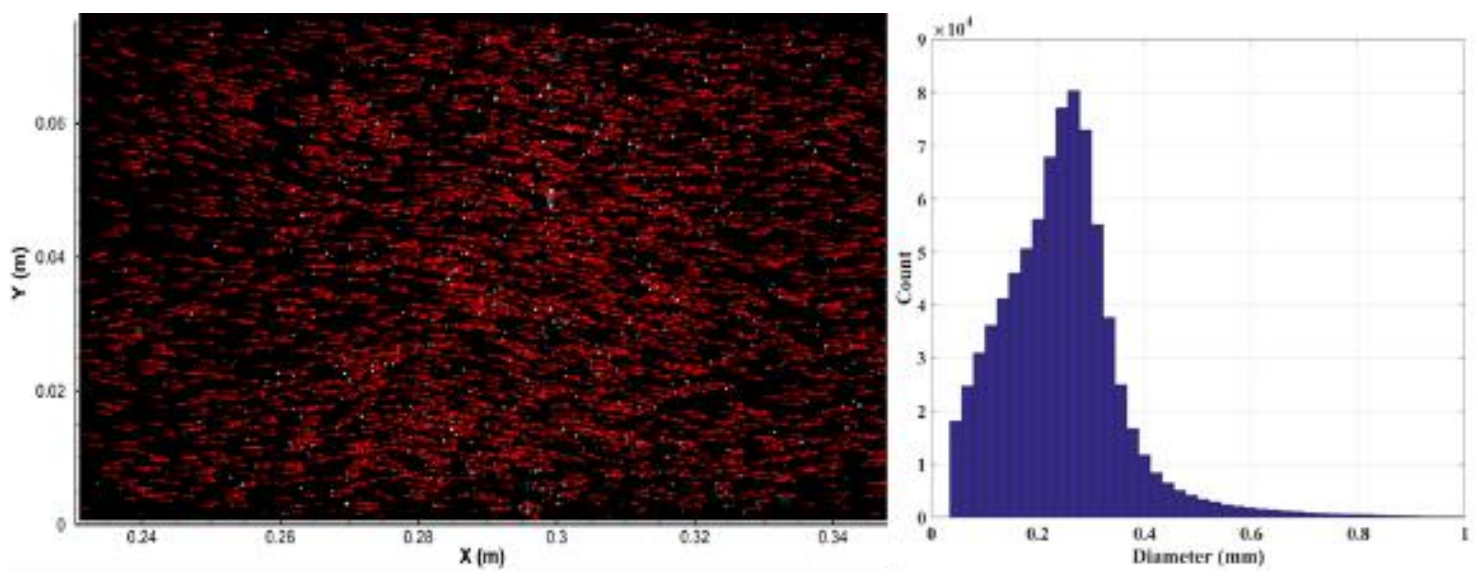

Figure 9-3. Left: instantaneous-velocity vector field overlaid on an experimental image. Right: histogram of particle sizes.

Figure 9-4 displays the particle distribution of $u$ and $v$ velocities for the duration of the test. The velocity distribution for the $u$ and $v$ components showed the results expected within a channel, i.e., $u$-component peaks around $1.12 \mathrm{~m} / \mathrm{s}$ and $v$-component centered at about $0 \mathrm{~m} / \mathrm{s}$.
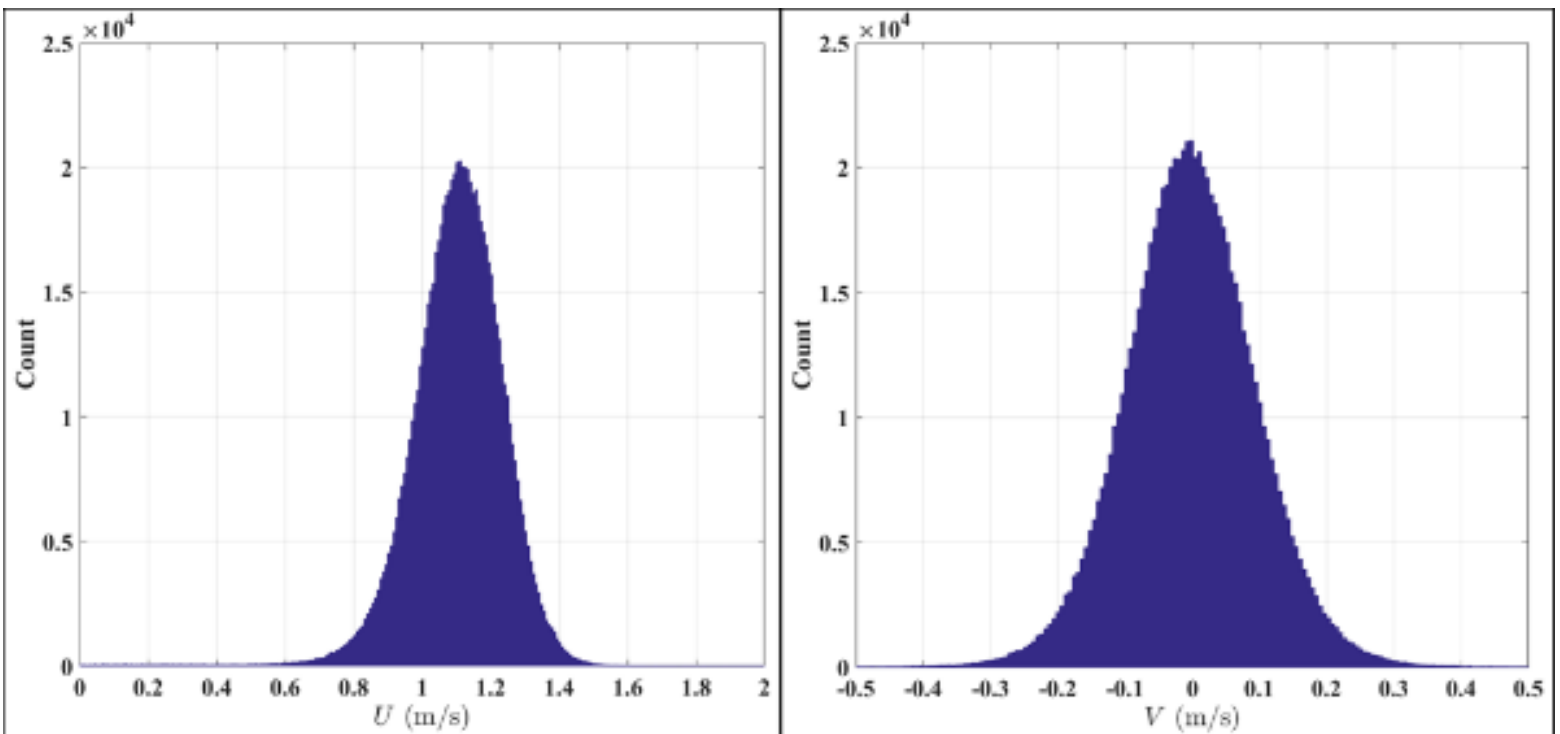

Figure 9-4. Histograms of (left) particle $u$ velocity component and (right) particle $v$ velocity component.

Results of PTV measurements allowed for the particle concentration to be determined along a vertical line. Figure 9-5 shows the profile of particle concentration along a vertical line normalized with the total particles counted. This particle concentration profile was defined as the number of particles counted within a vertically thin area at the center of the test section. In addition to knowing the particle-concentration profile at the center of the middle section, the particles entering and exiting the middle section were determined by the two particle-tracking systems installed. For this specific Reynolds number $(\operatorname{Re}=5,077), 2,361,300$ particles were counted entering, and $2,099,509$ were counted exiting the section. This gives an average of $11.08 \%$ particle deposition 
within the test facility repeated over three tests. The average is computed as the percentage difference between the particles entering and exiting the test section.

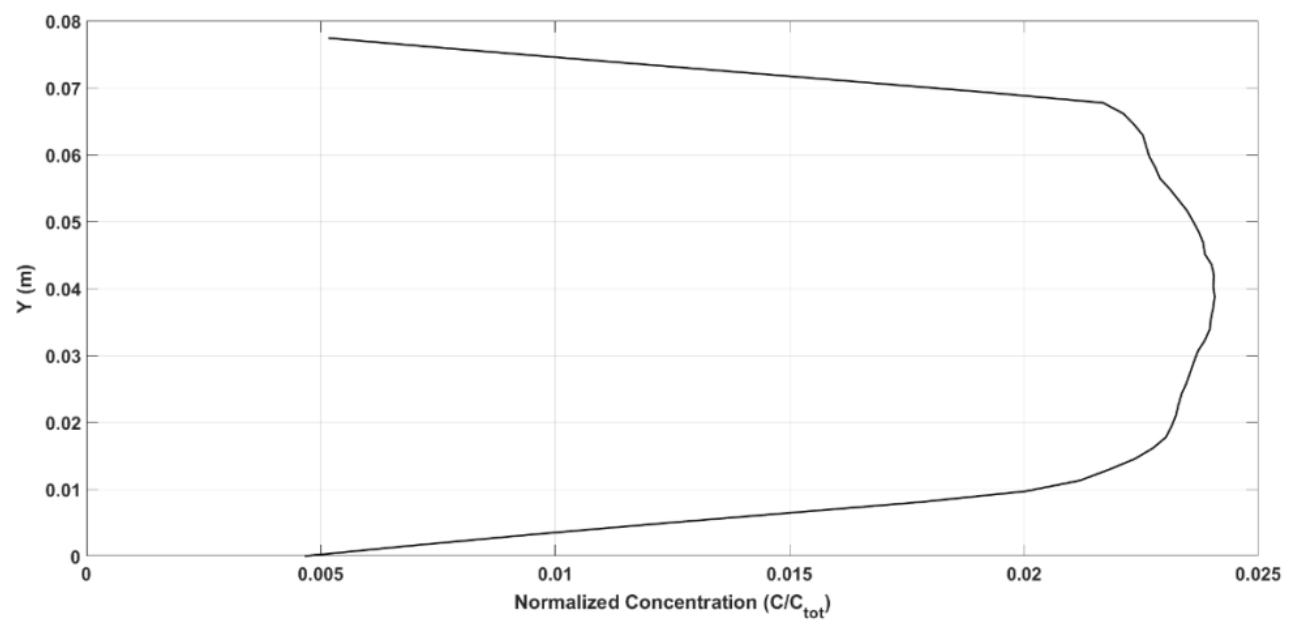

Figure 9-5. Normalized particle concentration along a vertical line profile.

\subsection{UNCERTAINTY ANALYSIS ON VELOCIMETRY TECHNIQUES}

The uncertainty sources associated with the measurement of particle displacement and calculated velocity include the particle-fluid behavior and calibration, but also random errors in velocity vectors. To minimize the error due to particle-fluid behavior, the Stokes number of the particle was such that, $S t k<0.1$. The particles used during testing have a Stokes number of approximately 0.00308 . The particle diameter is carefully chosen to be sufficiently large enough to produce quality images. The calibration images were captured using a high-precision LaVision target with known dimensions.

The particle velocity expressed simply can be written as,

$$
U_{p}=\alpha \frac{\Delta X}{\Delta t}
$$

where $\Delta X$ is the particle displacement in pixel, and $\alpha$ is the image magnification factor. The percent standard estimation of uncertainty in the velocity can be expressed as,

$$
S E_{\%}=\sqrt{\left(U_{\% \alpha}\right)^{2}+\left(U_{\% X}\right)^{2}+\left(U_{\%}\right)^{2}}
$$

where $U_{\% \alpha}, U_{\% X}$, and $U_{\% t}$ are the percent standard-uncertainty-associated magnification factor, particle displacement, and time interval. The SE\% is estimated to be less than $2 \%$ for all velocity vectors calculated. This method, described in Sabharwall et al. (2013), was used to estimate the uncertainties from the PIV measurements. Further analysis will be done to compare PIV and PTV results. 


\section{PRELIMINARY SIMULATION RESULTS}

This section presents a numerical study of particle transport and deposition in a channel. From the point of view of computational simulation, the goal of the project is to reproduce particle behavior in computational simulation as verified by experiment. Validated models can be employed to predict particle behavior for the given geometric and flow conditions. As a first step a straight horizontal channel, one of simplest shapes found in the GFR FPVS and GFR Primary system, is considered, and particle transport and deposition in the channel flow are investigated. It is established that turbulence deposition and gravity settling are two dominant forces exerted on the particles in the duct flow. Simulation will reproduce these two effects by using a Lagrangian approach for particles and a Eulerian approach for fluids. In predicting particle behavior in the Lagrangian approach, understanding the behavior of fluid is important because most of the forces exerted on the particles are related to the local quantity of velocity, pressure, the turbulence kinetic energy of a fluid, such as drag force, lift force, and turbophoresis. Choosing an appropriate turbulence model to solve for fluid becomes a priority in estimating particle trajectories. This section describes steps to identify the most suitable turbulence model for simulating the fluid flow within the proof-of-concept channel. These steps include comparisons of profiles of numerical results obtained from simulations of fully developed flows and developing flows to experimental data and available results from literature.

\subsection{EULERIAN APPROACH FOR FLUID}

\subsubsection{Turbulence Model for Fluid Flow}

Performing flow-behavior analysis in a square channel can be a challenging problem because the flow is confined with walls. Ordinary Reynolds-Averaged Navier-Stokes (RANS) models, such as k- $\varepsilon$ and k- $\omega$, cannot directly be employed because these models do not consider near-wall effects and anisotropic turbulence, some important factors in channel flow.

Therefore, advanced models have been implemented for this case. The modified low Reynolds number $\mathrm{k}-\varepsilon$ model introduces damping factors $f$, along with additional terms, modifying the constants $\mathrm{C}_{\mu}, \mathrm{C}_{\epsilon 1}, \mathrm{C}_{\epsilon 2}$ to account for low Reynolds number effects. The $f_{\mu}$ factor is a damping function to account for near-wall effect. The functions $f_{1}, f_{2}$ and, in some cases, $\mathrm{D}$ and $\mathrm{E}$ are included in the low-Reynolds closure models to fit a model valid at the wall (Hrenya, 1995). Steady-state, incompressible low-Reynolds-number two-equation RANS model can be expressed in generalized form, as:

$$
\begin{gathered}
\frac{\partial\left(U_{i}\right)}{\partial x_{i}}=0 \\
\frac{\partial\left(U_{i} U_{j}\right)}{\partial x_{j}}=-\frac{\partial \hat{P}}{\partial x_{i}}+\frac{\partial}{\partial x_{i}}\left[v\left(\frac{\partial U_{j}}{\partial x_{i}}+\frac{\partial U_{j}}{\partial x_{i}}\right)-\overline{u_{\imath}^{\prime} u_{j}^{\prime}}\right] \\
\frac{\partial\left(U_{i} k\right)}{\partial x_{i}}=\frac{\partial}{\partial x_{i}}\left[\left(v+\frac{v_{t}}{\sigma_{k}}\right) \frac{\partial k}{\partial x_{i}}\right]+P_{k}-(\tilde{\epsilon}) \\
\frac{\partial\left(U_{i} \tilde{\epsilon}\right)}{\partial x_{i}}=\frac{\partial}{\partial x_{i}}\left[\left(v+\frac{v_{t}}{\sigma_{\epsilon}}\right) \frac{\partial \tilde{\epsilon}}{\partial x_{i}}\right]+C_{\epsilon 1} f_{1} \frac{\tilde{\epsilon}}{k} P_{k}-C_{\epsilon 2} f_{2} \frac{\tilde{\epsilon}^{2}}{k}+E
\end{gathered}
$$

where $U_{i}$ is averaged velocity, $\overline{u_{\imath}^{\prime} u_{\jmath}^{\prime}}$ is averaged Reynolds stress, $v$ is kinematic viscosisty, $v_{T}$ is turbulence viscosisty, $k$ is turbulence kinetic energy (TKE), $\tilde{\epsilon}$ is modified dissipation rate for TKE, 
$\tilde{\epsilon}=\epsilon-D . P_{k}$ is a production term, $f_{\mu}, f_{1}, f_{2}$ are damping factors, and $\mathrm{C}_{\mu}, \mathrm{C}_{\epsilon 1}, \mathrm{C}_{\epsilon 2}, \sigma_{k}, \sigma_{\epsilon}$ are closure coefficients for the $k-\epsilon$ model, shown in Table 10-1.

Table 10-1. Closure coefficient for k- $\varepsilon$ model.

\begin{tabular}{|c|c|c|c|c|}
\hline $\mathbf{C}_{\boldsymbol{\mu}}$ & $\mathbf{C}_{\boldsymbol{\epsilon} \mathbf{1}}$ & $\mathbf{C}_{\boldsymbol{\epsilon} \mathbf{2}}$ & $\boldsymbol{\sigma}_{\mathbf{k}}$ & $\boldsymbol{\sigma}_{\boldsymbol{\epsilon}}$ \\
\hline 0.09 & 1.44 & 1.92 & 1.0 & 1.3 \\
\hline
\end{tabular}

In this study, the model that is the best fit to the experimental study was determined. Three candidates suggested by Launder and Sharma (1974), Lam and Bremhorst (1991) and Lien and Leschziner (1993) are compared with experimental data and standard k- $\varepsilon$ model (STD) by Launder and Spalding (1974) in this system. The differences between the models are summarized in Table 10-2 and Table 10-3.

Table 10-2 Terms and boundary condition for each model.

\begin{tabular}{|c|c|c|c|c|c|}
\hline Model & $v_{t}$ & $\boldsymbol{P}_{\boldsymbol{k}}$ & D & $\mathbf{E}$ & Wall BC \\
\hline Standard & \multirow{4}{*}{$C_{\mu} f_{\mu} \frac{k^{2}}{\epsilon}$} & \multirow{4}{*}{$-\overline{u_{\imath}^{\prime} u_{\jmath}^{\prime}} \frac{\partial U_{i}}{\partial x_{j}}$} & 0 & 0 & Wall function \\
\hline $\mathbf{L S}$ & & & $2 v\left(\frac{\partial \sqrt{k}}{\partial y}\right)^{2}$ & $2 v v_{t}\left(\frac{\partial^{2} U}{\partial y^{2}}\right)^{2}$ & $\mathrm{k}=\epsilon=0$ \\
\hline $\mathbf{L L}$ & & & 0 & 0 & $\mathrm{k}=\epsilon=0$ \\
\hline LB & & & 0 & 0 & $\begin{aligned} \frac{\mathrm{dk}}{\mathrm{dy}} & =0, \epsilon=v \frac{\mathrm{d}^{2} k}{d y^{2}} \\
\text { Or, } k & =0, \frac{\mathrm{d} \epsilon}{\mathrm{dy}}=0\end{aligned}$ \\
\hline
\end{tabular}

Table 10-3 Damping coefficient for each model.

\begin{tabular}{|c|c|c|c|}
\hline Model & $\boldsymbol{f}_{\boldsymbol{\mu}}$ & $\boldsymbol{f}_{\mathbf{1}}$ & $\boldsymbol{f}_{\mathbf{2}}$ \\
\hline Standard & 1 & 1 & 1 \\
\hline $\mathbf{L S}$ & $\exp \left[-3.4 /\left(1+R e_{t} / 50\right)^{2}\right]$ & 1 & $1-0.3 \exp \left(-\mathrm{Re}_{t}^{2}\right)$ \\
\hline $\mathbf{L L}$ & {$\left[1-\exp \left(-0.016 l_{n}^{*}\right)\right] /\left[1-\exp \left(-0.263 l_{n}^{*}\right)\right]$} & $1+\frac{P_{k}^{\prime}}{P_{k}}$ & $1-0.3 \exp \left(-R e_{t}^{2}\right)$ \\
\hline $\mathbf{L B}$ & $\left.\left[1-\exp \left(-0.0165 l_{n}^{*}\right)\right]^{2}\left(1+20.5 R e_{t}\right)\right]$ & $1+\left(\frac{0.05}{f_{\mu}}\right)^{3}$ & $1-\exp \left(-R e_{t}^{2}\right)$ \\
\hline
\end{tabular}

In Tables 10-2 and 10-3, LS stands for Launder-Sharma, LL stands for Lien-Leschziner, LB stands for Lam-Bremhorst, $R e_{t}=\rho k^{2} / \mu \epsilon, l_{n}^{*}$ is distance from wall, $l_{n}^{*}=l_{n} k^{0.5} / v$ is normalized distance from wall and $P_{k}^{\prime}=\frac{C_{\epsilon 2} k^{3 / 2}}{3.53 l_{n}\left[1-\exp \left(-0.63 l_{n}^{*}\right)\right]} \exp \left(-0.00222 l_{n}^{*}\right)$. 


\subsubsection{Computational Methodology}

Steady-state computational fluid dynamics (CFD) simulation is conducted using OpenFOAM $v 6$, (open source CFD, www.openfoam.org), which supports an easy-to-modify turbulence model on demand. Its built-in simpleFoam solver is chosen as a steady-state solver.

Figure 10-1 is a schematic diagram of the domain used in the simulation. First, fully developed flow is investigated applying cyclic boundary conditions at the inlet and exit of the computational domain. Many papers deal with a square-duct flow using the Direct Numerical Solution (DNS) technique. Among them, a DNS study by Gavrilakis (1992) had conditions like this study and is used as a reference.

Mesh is generated by blockMesh, a built-in program in OpenFOAM $v 6$. A grid-independence test is also conducted. Grid independence is tested from a $20 \times 20$ to a $160 \times 160$ cross-section mesh. It is determined that $60 \times 60$ is the optimal size for the mesh for the test section cross-section. A grid near the wall is of small size while one far from that wall has a larger size. Grid-expansion ratio is referred to as the ratio of the largest grid at the center to smallest one adjacent to the wall (specified as 40 in this study). The inlet of Figure 10-1 represents a quadrant of mesh. A mesh of 300 uniformly divided grids are employed along streamwise direction.

The physical properties of the fluid and boundary conditions, such as flow rates and Reynolds numbers, for the numerical calculations are identical to the experimental data listed in Table 9-1 and Table 9-2, respectively.

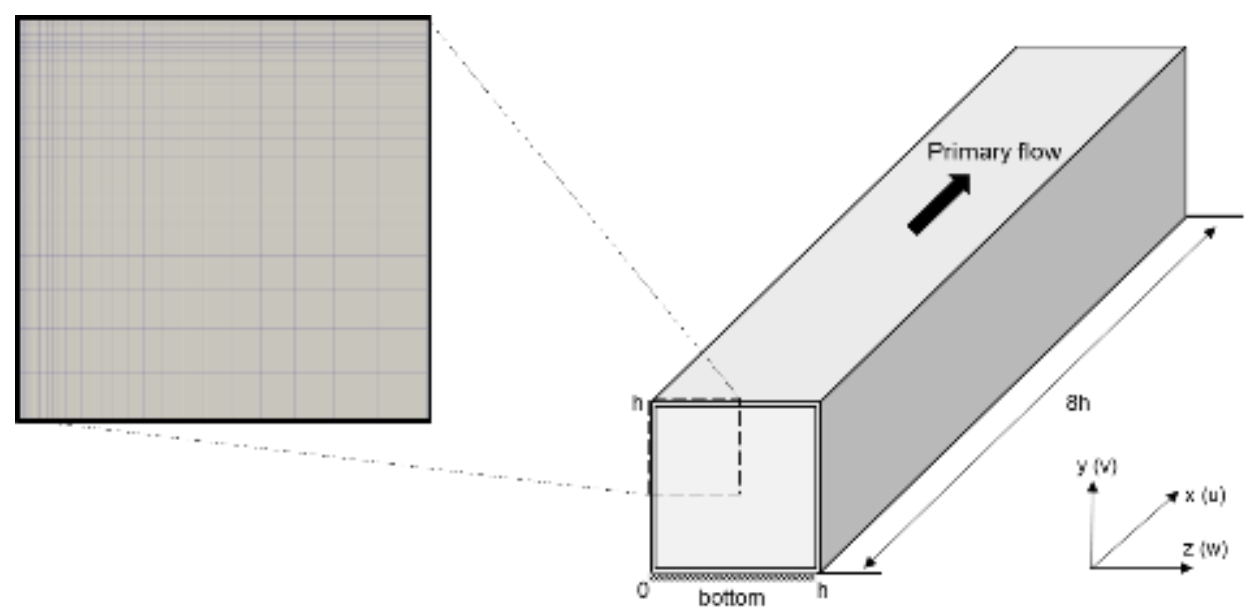

Figure 10-1. Schematic geometry of the duct.

Next, developing flow is studied and compared with experimental data. The experimental channel has three test sections; each has a 76.2-mm (3-in) square cross-section and 609.6-mm (24 in) in length (see Figure 6-1), however the current study only solved for the middle section numerically. The channel extends in the x-direction, eight times height (h) of the square channel. The simulation domain is built upon the geometrical dimensions of the experimental facility while upstream flow characteristics of the square channel obtained by PIV measurements are used as boundary conditions. Since only one-dimensional (1D) profiles of velocity along normal direction is measured at the cross-section surface during the preliminary experiment, two-dimensional (2D) 
profiles are interpolated from 1D profiles, assuming axisymmetric. Boundary conditions are specified in Table 10-4.

Table 10-4. Boundary condition specified in each case.

\begin{tabular}{|c|c|c|c|}
\hline Parameter & Inlet & Outlet & Side \\
\hline $\mathrm{U}$ & 2D profiles measured from exp. & Zero Gradient & No-slip \\
\hline $\mathrm{P}$ & Zero Gradient & Fixed Value; 0 & Zero Gradient \\
\hline $\mathrm{k}$ & 2D profiles measured from exp. & Zero Gradient & Table 10-2 \\
\hline$\varepsilon$ & Fixed value; 0 & Zero Gradient & Table 10-2 \\
\hline
\end{tabular}

The velocity, and TKE profiles $25 \mathrm{~cm}$ downstream of the inlet are compared with the experimental data at same distance from the inlet. If profiles achieved by PIV and simulation are similar, the model can be considered validated. TKE profiles are fully investigated because the amount of TKE injected at the inlet affects a fluid's behavior and TKE y diminished as fluid flows along the channel.

There are three experimental cases with different centerline Reynold numbers: 3,600, 5,100, and 6,100. All three cases are numerically reproduced and compared with the experimental data. The center-line flow Reynolds number $\left(\operatorname{Re}_{c}\right)$ is defined as:

$$
R e_{C}=\frac{U_{c} h}{v}
$$

where subscript "c" refers to centerline, $U_{c}$ is velocity at the center of the inlet, $\mathrm{h}$ is height of the square channel, and $v$ is the kinematic viscosity of the fluid.

\subsection{SIMULATION RESULTS AND DISCUSSION}

\subsubsection{Fully Developed Flow}

Figure 10-2 shows the fully developed streamwise velocity profiles along the middle section of the channel, i.e., mid-section, for different mesh sizes. Centerline velocity converges to an

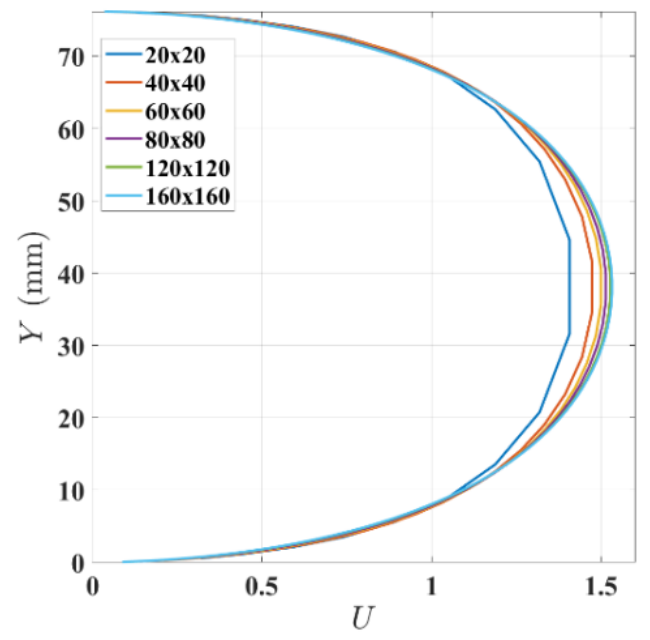

Figure 10-2 Streamline velocity with different mesh size $\mathrm{N} \times \mathrm{N}$. 
asymptotic value as the grid become finer. Considering computational power and measurement error, $60 \times 60$ mesh is determined to be the optimal mesh size in this study because the centerline
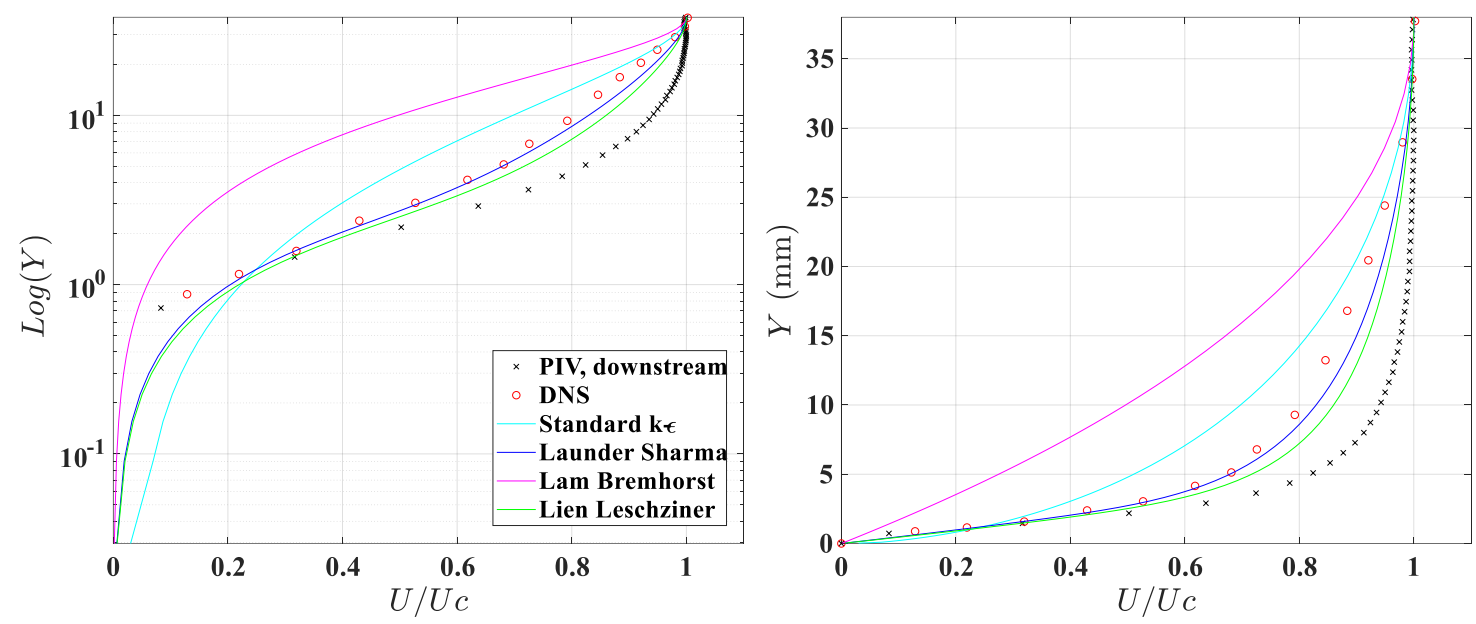

Figure 10-3. Comparison of streamwise velocity with different models. Log (Left) and linear (right) plot for location $y$.

velocity of this mesh size has below $2 \%$ deviation from that of the $160 \times 160$ mesh size.

Figure 10-3 represents streamwise velocity normalized to the centerline velocity at the mid-section for fully developed flow with different models. All turbulence models are conducted with $R e_{c}$ of 5,100. PIV profiles in the graph are the value estimated downstream of the channel. DNS profiles achieved from DNS (Gavrilakis, 1992) at $R e_{\tau}$ of 300, which is equal to $R e_{c}$ of 5,883. Because velocity is normalized to its maximum value, small deviations in the centerline Reynolds number do not change the simulation results much, and these results can be compared directly. The graph shows velocity profiles achieved from PIV is like while DNS (Gavrilakis, 1992) is bell-like downstream. A deviation between velocity profiles measured by PIV and those calculated by DNS means flow at downstream has not fully developed. Also, velocity profiles estimated by the standard k- $\varepsilon$ turbulence model have high a deviation from the DNS results, especially near the wall. This is the reason why a modified turbulence model is needed to simulate fluid flow. Velocity profiles estimated by the Launder-Sharma model looks like DNS results (Gavrilakis, 1992). This is in good agreement with discussions of Hrenya (1995) and Patel (1984) that suggested LaunderSharma model (Launder \& Sharma, 1974) as one of the best models to predict duct flows. 
Table 10-5 tabulates the ratio of centerline velocity to bulk velocity obtained by different methods. It is noted that centerline velocity is determined at the half-height of the channel, while the bulk velocity is the averaged velocity over an entire cross section. The ratio of the centerline velocity to bulk velocity obtained from the DNS results of Zhang et al (2015) is 1.33 at $R e_{\tau}$ of 5,883, while it is 1.7977 at $R e_{c}$ of 5,100 using the standard k- $\varepsilon$ model. On the other hand, Launder-Sharma and Lien-Leschziner models result in ratios of 1.37 and 1.33, respectively, almost identical to DNS data. From these results, it could be concluded that Launder-Sharma and Lien-Leschziner model have good agreement with the fully developed velocity profiles.

Table 10-5. Ratio of centerline velocity to bulk velocity at fully developed condition.

\begin{tabular}{|c|c|c|c|c|c|c|}
\hline & PIV & STD & LS & LB & LL & DNS \\
\hline$U_{C} / U_{b}$ & 1.191 & 1.797 & 1.372 & 2.081 & 1.332 & $\mathbf{1 . 3 3}$ \\
\hline
\end{tabular}

\subsubsection{Developing Flow at Downstream}

Figure 10-4 through Figure 10-7 represent normalized streamwise velocity and TKE profiles at the mid-section, $25 \mathrm{~cm}$ from the inlet for standard k- $\varepsilon$, Lam-Bremhorst, Launder-Sharma and Lien-Leschziner models. Since there is no DNS data for developing flow in duct flow, experimental data achieved is employed to validate the model. Comparisons are conducted for all three different centerline Reynolds numbers: 3,600, 5,100, and 6,100.

Figure 10-4 depicts velocity and TKE profiles estimated using the standard k- $\varepsilon$ model, showing overestimation of TKE generation near the wall, corresponding to a deviation of velocity profiles near the wall. On the other hand, velocity profiles estimated using the Launder-Sharma (Figure 10-6) and Lien-Leschziner (Figure 10-7) models match the best with the primary mean velocity when compared with experimental values. However, TKE is underestimated for all Reynolds numbers considered in this study. The TKE deviation between CFD value and PIV values becomes small as the Reynolds number increases. It might be expected that a Reynolds number below 6,000 is too small to use a low-Reynolds number model. The Lam-Bremhorst model (Figure 10-5) had a reasonable fit of TKE, except in the case of $R e=3,600$. Velocity profiles matched at the center of the channel, but the gradient of the velocity near the wall using the Lam-Bremhorst model did not agree well with the experimental results as well as the predictions using Launder-Sharma or the Lien-Leschziner models. Considering that particle deposition occurred at near the wall, this model might have a defect for estimating particle deposition rates.

From the results of fluid flow behaviors predicted by four different models and for three different Reynolds numbers, Launder-Sharma (Launder \& Sharma, 1974) and Lien-Leschziner (Lien \& Leschziner, 1993) models have the good performances in low-Reynolds-number flow range among the four models. 

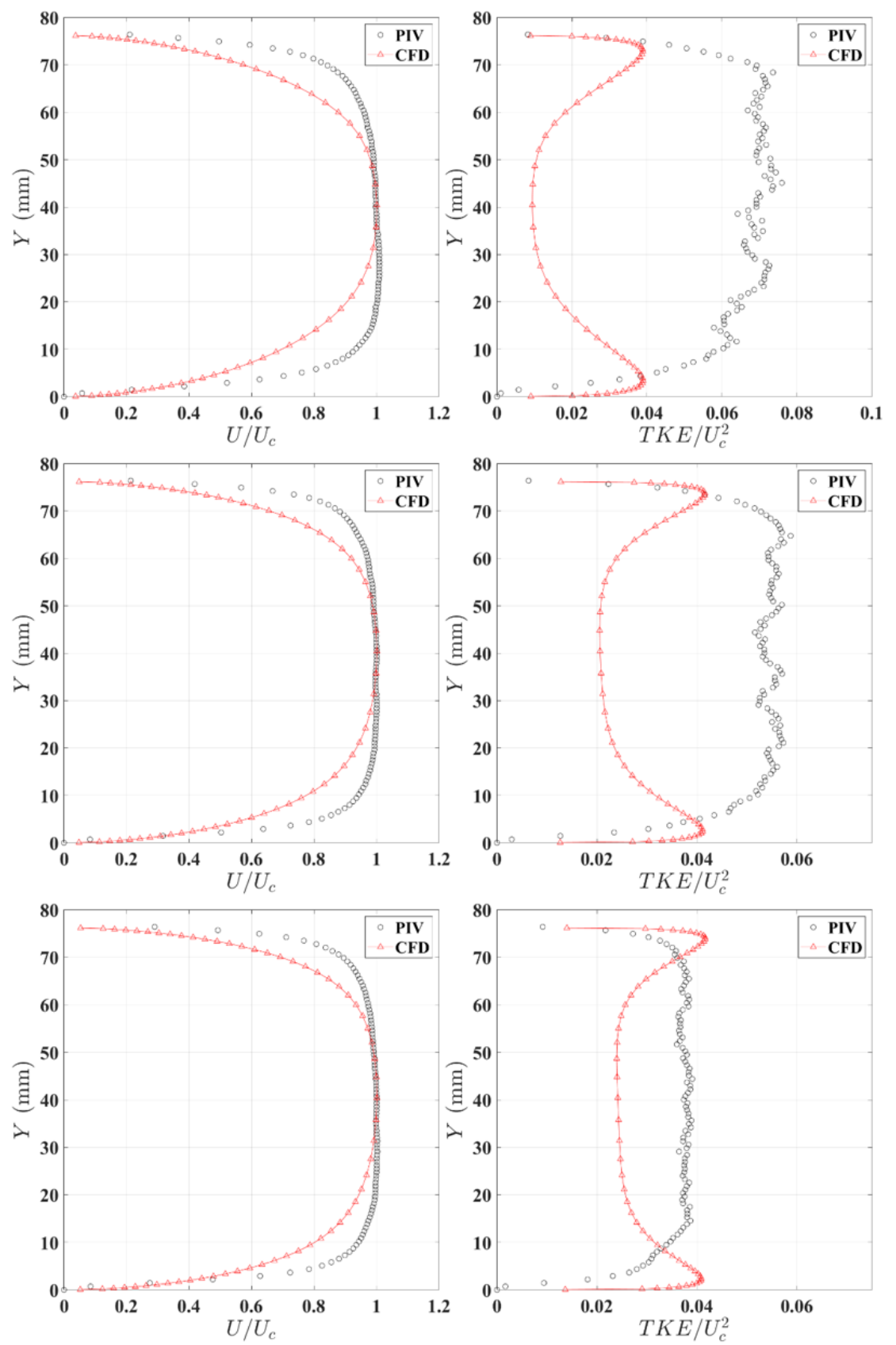

Figure 10-4. Comparisons between PIV and CFD in the downstream region of the channel with standard k- $\epsilon$ model (up) $R_{c}=3,600$, (middle) $\operatorname{Re}_{c}=5,100$ and (bottom) $\operatorname{Re}_{c}=6,100$. 

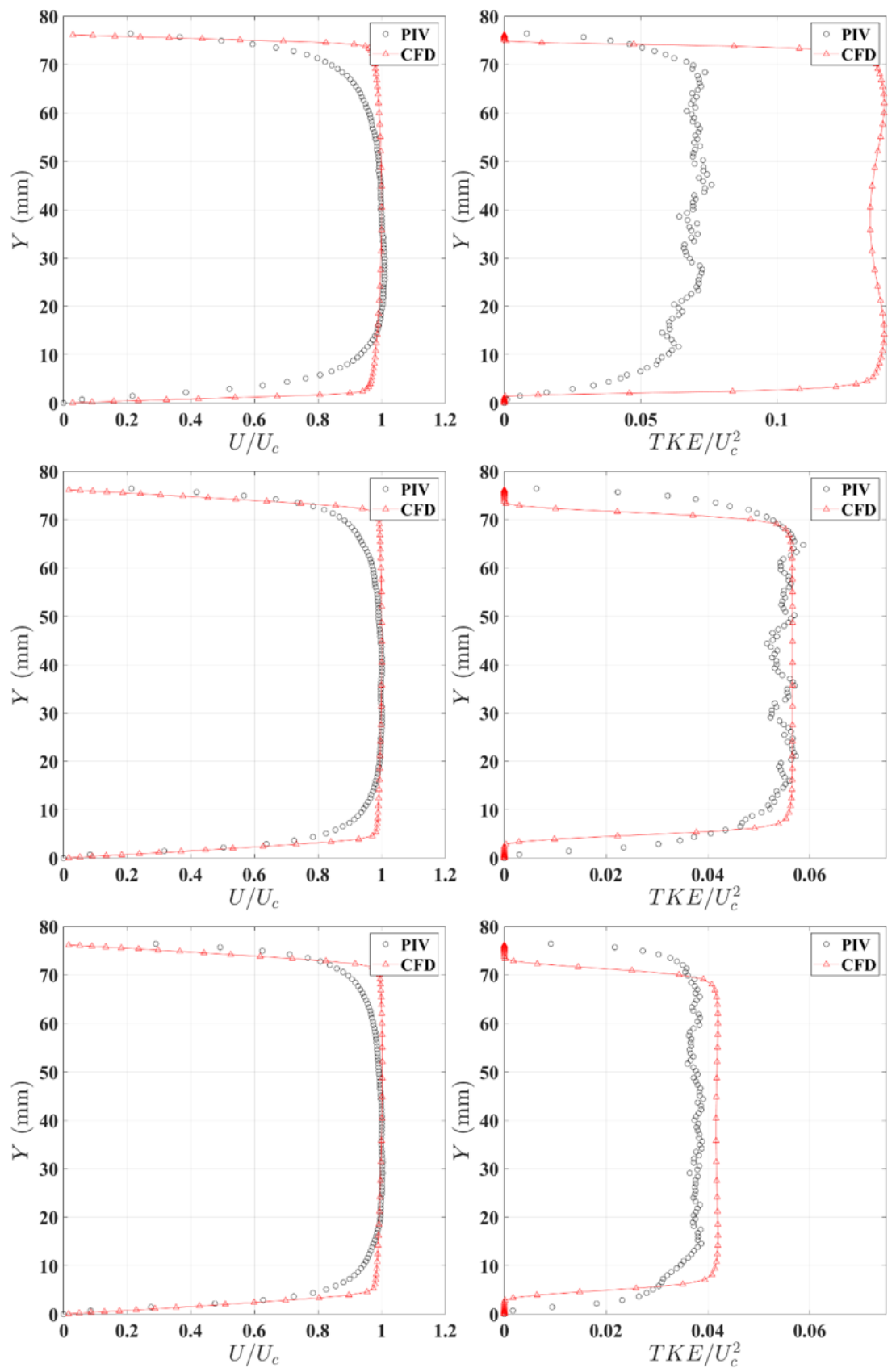

Figure 10-5. Comparisons between PIV and CFD in the downstream region of the channel with Lam-Bremhorst model (up) $\operatorname{Re}_{c}=3,600$, (middle) $\operatorname{Re}_{c}=5,100$ and (bottom) $\operatorname{Re}_{c}=6,100$. 

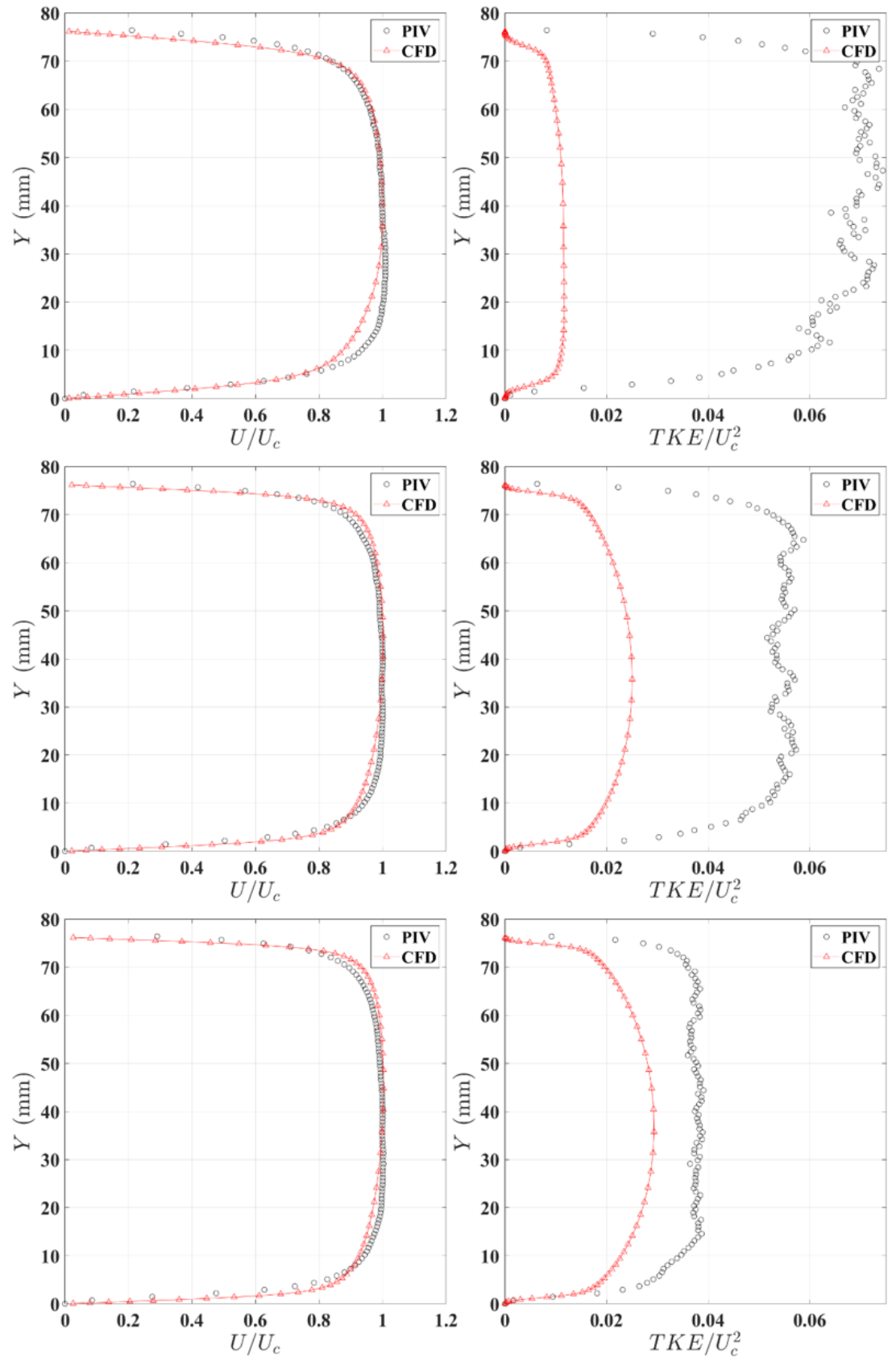

Figure 10-6. Comparisons between PIV and CFD in the downstream region of the channel with Laundar-Sharma model (up) $\operatorname{Re}_{c}=3,600$, (middle) $\operatorname{Re}_{c}=5,100$ and (bottom) $\operatorname{Re}_{c}=6,100$. 

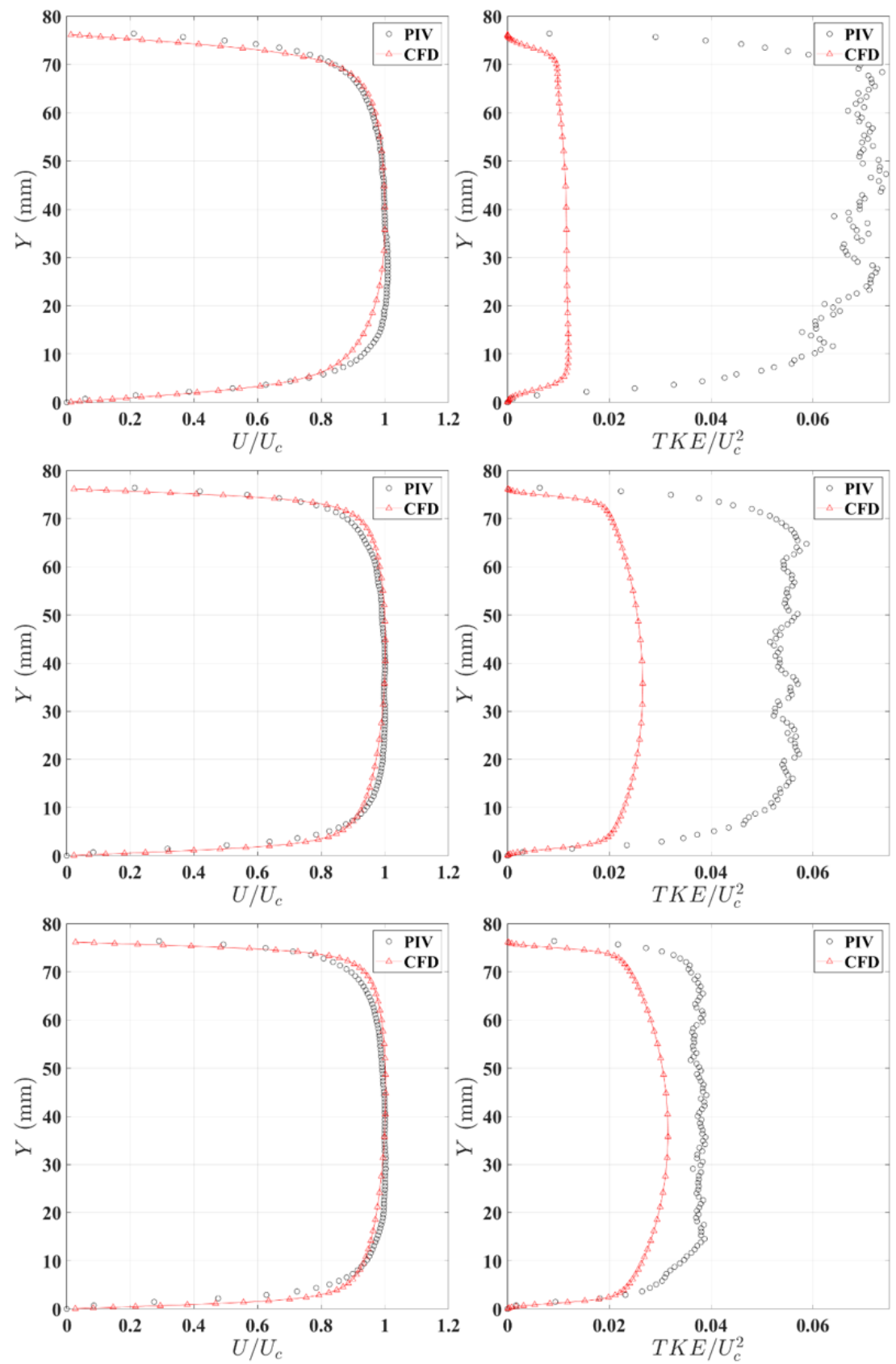

Figure 10-7. Comparisons between PIV and CFD in the downstream region of the channel with Lien-Leschziner model (up) $R e_{c}=3600$, (middle) $R e_{c}=5100$ and (bottom) $R e_{c}=6100$. 

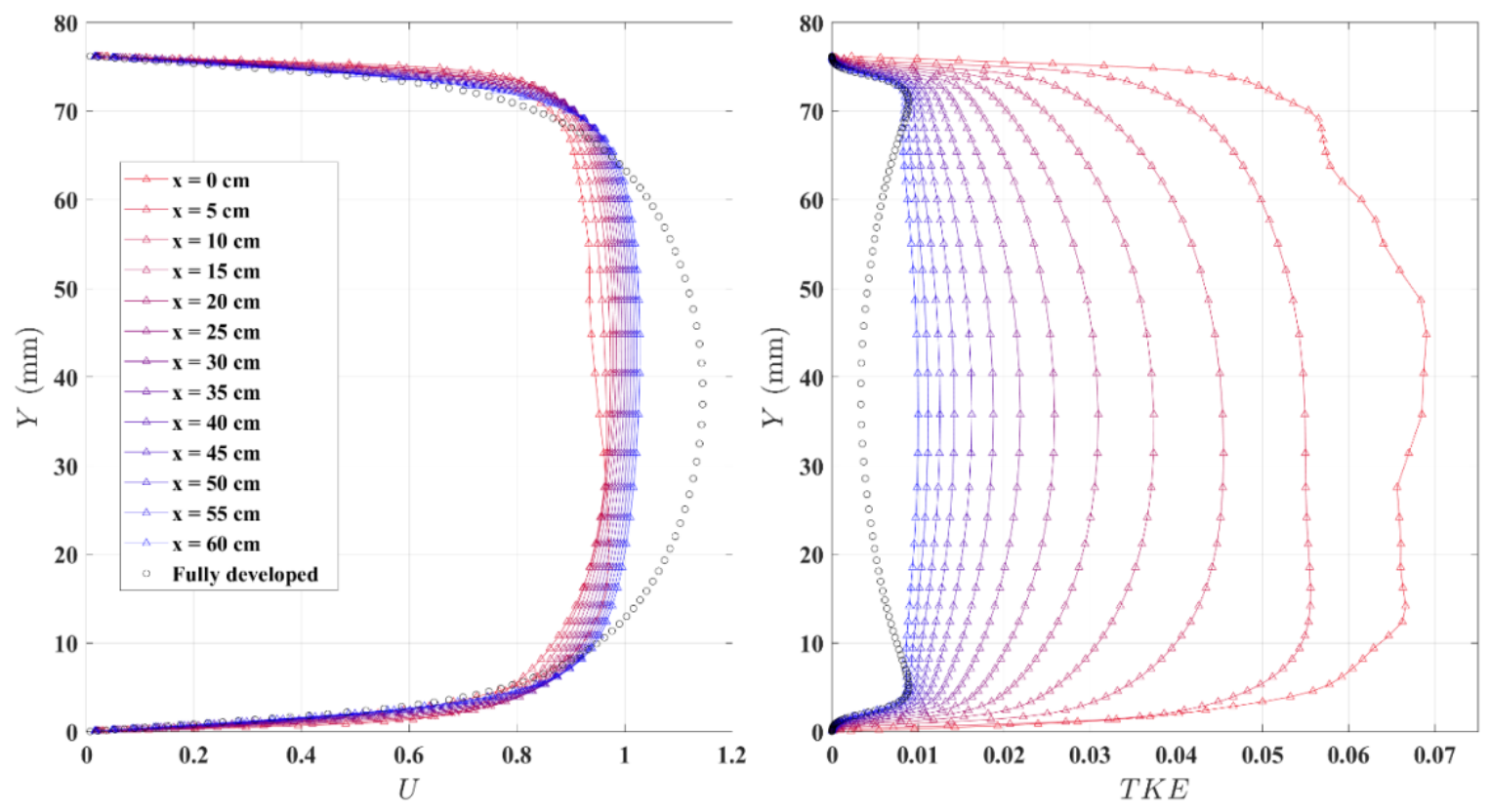

Figure 10-8. Evolution of velocity profiles, $U$ velocity (left) and turbulent kinetic-energy profiles (right) with different locations along $\mathrm{x}, \mathrm{z}=\mathrm{h} / 2$ with $\operatorname{Re}_{c}=5,100$, LS model is employed.

Figure 10-8 illustrates the evolutions of velocity and TKE along the flow direction in the proof of concept channel. Results of simulation using Launder-Sharma model evolved towards those of simulation of fully developed flow in ducts. Figure 10-8 shows mid-section velocity and TKE profiles at $\operatorname{Re}_{c}=5,100$ at every $5 \mathrm{~cm}$ increments along streamwise direction. Profiles near the inlet are indicated in red, while those at further downstream locations are indicated in blue. Profiles of fully developed flow simulations are shown as black dots. Velocity profiles increased to a maximum at the channel half-height as the momentum moves to the center. This agrees with bellshaped developed velocity profiles. On the other hand, TKE decreases in the streamwise direction. This tendency is observed both in experiments and simulations. It is also found that TKE profiles have two high peaks near the wall.

Secondary flow and its vortices are an important factor for particle deposition in duct flow. DNS simulation conducted by Gavrilakis (1992) and Zhang et al. (2015) suggest that secondary flow is about $1-2 \%$ of mean bulk velocity at diagonal corners of the channel. Geometries of the duct could be a significant factor affecting the transport and deposition of particles. Massless particle simulation with flow solved by DNS (Sharma \& Phares, 2006) determined that particles are rotating along vortices in the ducts due to secondary flow. Contour and arrows on Figure 10-9 represent the magnitude and direction of secondary velocity flows downstream. Red color indicates high magnitude of secondary flow while blue means no secondary flow. Results are shown for the LS model for $\mathrm{Re}=5,100$. It shows that the maximum secondary flow lies on one corner of the channel, having $0.3 \%$ of primary bulk velocity. While DNS results (Gavrilakis, 1992) 


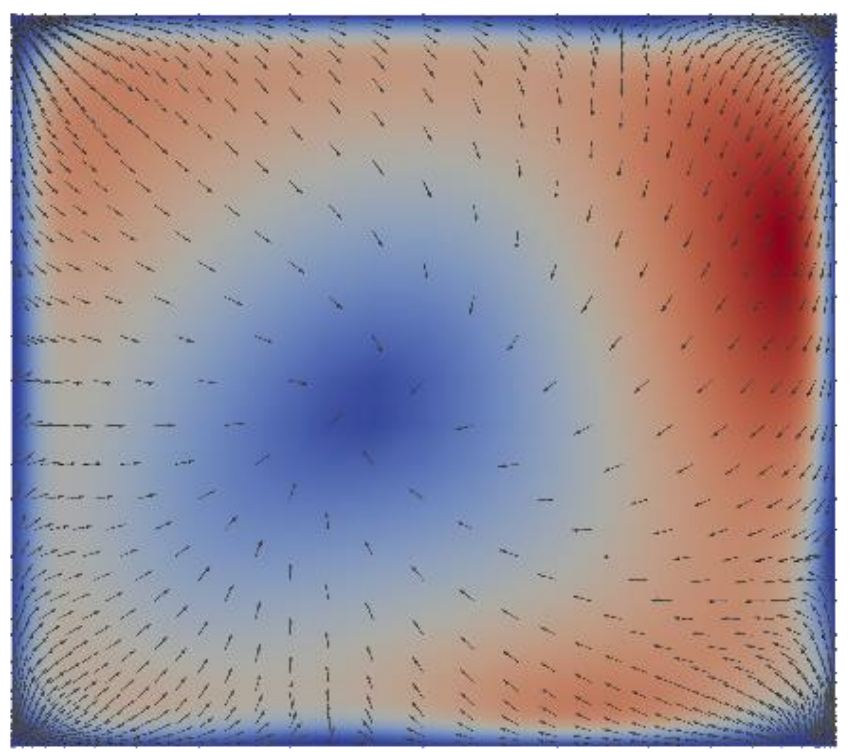

Figure 10-9. Secondary velocity contour at downstream of $R e_{c}=5,100$. The Launder-Sharma model is employed.

showed twin vortices at each corner, corner vortices are not seen in the current simulation. The contour shown in Figure 10-9 indicated that the Launder-Sharma model (Launder \& Sharma, 1974) did not reveal the secondary flow well. It is not clear the reason that vortices are not observed in our simulations. Further investigation is necessary. It is reported that the Reynolds stress model (RSM) or algebraic stress model (ARSM) could reproduce vortices similar to the result by DNS in a fully developed flow (Mompean, 1996). 


\section{SUMMARY AND FUTURE WORK}

A proof of concept test facility consisting of straight rectangular channel was fabricated to establish flow and particle deposition measurements. While the FPVS design detail for the VTR Cartridge Loop was not available, it was assumed that characterization of flow and particle deposition in rectangular channels in terms of non-dimensional parameters could be used to characterize flow and particle deposition in prototypical conditions. Scaling was necessary to facilitate visualization techniques like PIV and PTV to be used and to select a surrogate particle that might prevail in the FPVS. The prototypical GFR Cartridge Loop operates at high temperatures $\left(\sim 850_{0} \mathrm{C}\right)$ and at high pressures $(\sim 13 \mathrm{MPa})$. It is noted that the non-dimensional parameters used in the scaling approach can be further applied to the VTR GFR Cartridge Loop design. For example, fission gases and fission particles could be produced during irradiation tests and be present in the FPVS of VTR GFR Cartridge Loop. Phenomena, such as gas diffusion and mixing, transport, particle deposition and resuspension, could occur. The dust associated with GFRs is a safety issue that requires research and development in order to quantify fission product transport (Humrickhouse, 2011), and will be simulated in the VTR GFR Cartridge Loop.

Experimental measurements conducted in a proof-of-concept test facility have given preliminary results that indicate the non-intrusive optical measurement techniques of PIV and PTV can be applied in an investigation of the aerodynamic flow fields and particle deposition (Amini \& Hassan, 2009). A combination of PIV and PTV measurements in the proof-of-concept test facility showed that particle velocity decreases as particles move toward the wall. This can be observed in Figure 9-2 where velocity magnitude goes to zero and TKE increases near the wall. This will affect the deposition of particles and is dependent on the Reynolds number. PTV results provide information about particle size and velocity distribution. The particle diameter distribution agrees with known values. Future tests may require the identification of the diameter of particles composed of different materials, and the ability to measure such characteristics is important. Velocity-component distributions and particle-concentration profiles give statistics about deposition within the test section. It can also be observed from the concentration profile that near the wall, concentration is non-zero, as one would expect.

Future measurements includes performing the experiment at varying low and high Reynolds numbers to get insight on gravitational and turbulence effects on particle deposition. In addition, measurements on a surface wall to count and size particles will be implemented using highresolution cameras and optics paired with the Laser-Induced Fluorescence technique (Barth, et al., 2013; Kassab, et al., 2013). Once the control testing is complete, the surface will be modified with carbon nanotube sheets to determine the effects of the surface on deposition (Kim, et al., 2018). The measurement techniques of PIV, PTV, and LIF (Estrada-Perez, et al., 2011; Nguyen, et al., 2018; Nguyen, et al., 2018; Goth, et al., 2018; Nguyen, et al., 2019) will be applied to the FPVS of VTR GFR Cartridge Loop in the future. The idea is to measure the deposition of surrogate particles within the facility. In a gas-cooled reactor, debris and other particles can carry away fission products from the core under normal operation conditions. Being able to modify the wall surface within the facility can prevent exposure and increase safety.

Numerical simulations will be further explored with advanced models. Though LaunderSharma (Launder \& Sharma, 1974) and Lien-Leschziner (Lien \& Leschziner, 1993) models work well for primary velocity profiles, both in fully developed and developing flow, there are some shortcoming for these models to predict TKE profiles and secondary flow. It is necessary to implement advanced turbulence models, such as algebraic Reynolds stress model (Mompean, 
1996), to improve the prediction of TKE and secondary flows because these are important for calculating particle deposition rate in the duct flow. The Lagrangian approach for particles is to solve Newton's second law of motion for each particle. Three main forces on particles must be considered: gravity, drag (driven by both primary and secondary flows), and turbophoresis force, driven by a gradient of fluctuating velocity. The magnitude of turbophoresis is related to TKE, and it can be simulated by random-function generation. A continuous random-walk model and a stochastic Lagrangian model (Dehbi, 2009) will be employed in future work. Injecting millions of particles into the proof concept test channel and counting the number of particles exiting the test section the particle deposition on the walls can be determined.

Detailed experimental measurements and numerical simulations of particle transport and deposition in the proof-of-concept facility will be further described in the later studies. Once the physics is successfully observed and modeled within the proof-of-concept test facility, the measurement techniques will be applied to the FPVS of VTR GFR Cartridge Loop. 


\section{REFERENCES}

A. V. Obabko, P. F. Fisher, T. J. Tautges, V.M. Goloviznin, M.A. Zaytsev, V.V. Chudanov, V.A. Pervichko, A.E. Aksenova, S. Karabasov, 2012. Large Eddy Simulation of Thermo-Hydraulic Mixing in a T-Junction. Nuclear Reactor Thermal Hydraulics and Other Applications, 25.

Amini, N. \& Hassan, Y. A., 2009. Measurements of jet flows impinging into a channel containing a rod bundle using dynamic PIV. International Journal of Heat and Mass Transfer, 52(23-24), pp. 5479-5495.

Balderrama, S. A. et al., 2019. Versatile Test Reactor: Irradiation Testing Vehicles for Fast Reactors and Proposed Experimental Loadings, Idaho Falls, Idaho: Idaho National Laboratory.

Barth, T., Lecrivain, G. \& Hampel, U., 2013. Particle deposition study in a horizontal turbulent duct flow using optical microscopy and particle size spectrometry. Journal of Aerosol Science, Volume 60, pp. 4754.

Center, N. N. D., National Nuclear Data Center. Available at: https://www.nndc.bnl.gov/

Choi, H. \& Schleicher, R. W., 2017. The Energy Multiplier Module (EM2): Status of Conceptual Design. Nuclear Technology, Volume 200, pp. 106-124.

Dehbi, A., 2009. A stochastic Langevin model of turbulent particle dispersion in the presence of thermophoresis. International Journal of Multiphase Flow, Volume 35, pp. 219-226.

Eckstein, A. \& Vlachos, P. P., 2009. Digital particle image velocimetry (DPIV) robust phase correlation. Measurement Science and Technology, Volume 20.

Estrada-Perez, C. E., Hassan, Y. A. \& Tan, S., 2011. Experimental characterization of temperature sensitive dyes for laser induced fluorescence thermometry. Review of Scientific Intruments, 82(7).

Gavrilakis, S., 1992. Numerical simulation of low-Reynolds-number turbulent flow through a straight square duct. Journal of Fluid Mechanics, Volume 244, p. 101-129.

Gicking, A., 2012. Neutron Capture Cross Sections of Cadmium Isotopes, Oregon State University.

Goth, N., Jones, P., Nguyen, T., Vaghetto, R., Hassan, Y., Salpeter, N., Merzari, E., 2018. PTV/PIV measurements of turbulent flows in interior subchannels of a 61-pin wire-wrapped hexagonal fuel bundle. International Journal of Heat and Fluid Flow, Volume 71, pp. 295-304.

Haynes, M., Moreno, E. \& Owens, M., 2017. Evaluation and Testing of HTGR Reactor Building Response to Depressurization Accidents, U.S. Department of Energy.

Hrenya, B. C. S., 1995. Comparison of low Reynolds number k- $\varepsilon$ turbulence models in predicting fully developed pipe flow. Chemical Engineering Science, 50(12), pp. 1923-1941.

Humrickhouse, P. W., 2011. HTGR Dust Safety Issues and Needs for Research and Development. Idaho Falls: Idaho National Laboratory.

Kassab, A. S., Ugaz, V. M., King, M. D. \& Hassan, Y. A., 2013. High Resolution Study of Micrometer Particle Detachment on Different Surfaces. Aerosol Science and Technology, 47(4), pp. 351-360.

Kim, H., Park, S., Park, C., Le, T., Lee, S., Ha, T., Kim, H., Kim, J., Lee, C., Yoon, H., 2018. Surfacemodified polymer nanofiber membrane for high-efficiency microdust capturing. Chemical Engineering Journal, Volume 339, pp. 208-213.

Kliem, S., 2007. Experiments at the mixing test facility ROCOM for benchmarking of CFD codes. Nuclear Engineering and Design, Vol 238(3), pp. 566-576.

Lam, C. K. G. \& Bremhorst, K., 1981. A modified form of the k- $\varepsilon$ model for predicting wall turbulence, Journal of Fluids Engineering, 103. 456. 
Launder, B. E. \& Sharma, B. I., 1974. Application of the energy dissipation model of turbulence to the calculation of flows near a spinning disk. Lett. Heat Mass Transfer, 1, 131 (1974).

Launder, B.E. \& Spalding, D.B., 1974. The numerical computation of turbulent flows. Computer methods in applied mechanics and engineering, 3(2):269-289.

Lien, F. S. \& Leschziner, M.A., 1993. A Pressure-Velocity Solution Strategy for Compressible Flow and Its Application to Shock/Boundary-Layer Interaction Using Second-Moment Turbulence Closure. Journal of Fluids Engineering, 115, 717.

Moffat, R. J., 1988. Describing the Uncertainteis in Experimental Results. Experimental Thermal and Fluid Science, Volume 1, pp. 3-17.

Mompean, G. M. D., 1996. On predicting the turbulence-induced secondary flows using nonlinear k- $\varepsilon$ models. Physics of Fluids, Volume 8, pp. 1856-1868.

Nguyen, T., Goth, N., Jones, P., Vaghetto, R., Hassan, Y.A., 2018. Stereoscopic PIV measurements of near-wall flow in a tightly packed rod bundle with wire spacers. Experimental Thermal and Fluid Science, Volume 92, pp. 420-435.

Nguyen, T., Kappes, E., King, S., Hassan, Y.A., Ugaz, V., 2018. Time-resolved PIV measurements in a low-aspect ratio facility of randomly packed spheres and flow analysis using modal decomposition. Experiments in Fluids, 59(8), p. 127.

Nguyen, T., Muyshondt, R., Hassan, Y. \& Anand, N., 2019. Experimental investigation of cross flow mixing in a randomly packed bed and streamwise vortex characteristics using particle image velocimetry and proper orthogonal decomposition analysis. Physics of Fluids, 31(2), p. 025101.

Northrup, M. A., Kulp, T. J. \& Angel, S. M., 1991. Fluorescent particle image velocimetry: application to flow measurement in refractive index-matched porous media. The Optical Society, 30(21), p. 30343040.

Peng, W., Zhen, Y., Yang, X. \& Yu, S., 2013. Graphite dust deposition in the HTR-10 steam generator. Particuology, 11(5), pp. 533-539.

Peurrung, L. M., Rashidi, M. \& Kulp, T. J., 1995. Measurement of porous medium velocity fields and their volumetric averaging characteristics using particle tracking velocimetry. Chemical Engineering Science, 50(14), pp. 2243-2253.

Raffel, M., Willert , C. E., Wereley, S. \& Kompenhans, J., 2007. Particle Image Velocimetry: A Practical Guide, Springer.

Sabharwall, P., Conder, T., Skifton, R., Stoots, C., Kim, E. S., 2013. PIV Uncertainty Methodologies for CFD Code Validation at the MIR Facility, Idaho Falls: Idaho National Laboratory.

Salvetat, J. P., Bonard, J.M., Thomson, N.H., Kulik, A.J., Forró, L., Benoit, W., Zuppiroli, L., 1999. Mechanical properties of carbon nanotubes. Applied Physics A, pp. 255-260.

Sciacchitano, A., Neal, D., Smith, B., Warner, S., Vlachos, P., Wieneke, B., Scarano, F., 2015. Collaborative framework for PIV uncertainty quantification: comparative assessment of methods. Measurement Science and Technology, 26(7).

Sharma, G. \& Phares, D. J., 2006. Turbulent transport of particles in a straight square duct. International Journal of Multiphase Flow, Volume 32, pp. 823-837.

Westerweel, J., 1994. Efficient Detection of Spurious Vectors in Particle Image Velocimetry Data. Experiment in Fluids, 16(3), pp. 236-247.

Westerweel, J., Dabiri, D. \& Gharib, M., 1997. The effect of a discrete window offset on the accuracy of cross-correlation analysis of digital PIV recordings. Experiments in Fluids, 23(1), pp. 20-28. 
Yang, S. R., Kappes, E., Nguyen, T., Vaghetto, R., Hassan, Y., 2018. Experimental study on 1/28 scaled NGNP HTGR reactor building test facility response to depressurization event. Annals of Nuclear Energy, Volume 114, pp. 154-164.

Yildiz, O. \& Bradford, P. D., 2013. Aligned carbon nanotube sheet high efficiency particulate air filters. Carbon, Volume 64, pp. 295-304.

Young, J. \& Leeming, A., 1997. A theory of particle deposition in turbulent pipe flow. Journal of Fluid Mechanics, Volume 340, pp. 129-159.

Zhang, T., Yu, S., Peng, W., Sun, Q., Jiang, Y., Shid, Q., 2017. Resuspension of multilayer graphite dust particles in a high temperature gas cooled reactor. Nuclear Engineering and Design, Volume 322, pp. 497-503.

Zhang, H., Trias, F.X., Gorobets, A., Tan, Y., Olivaa, A., 2015. Direct numerical simulation of a fully developed turbulent square duct flow up to $R e_{\tau}=1200$. International Journal of heat and fluid flow 54 , 258. 